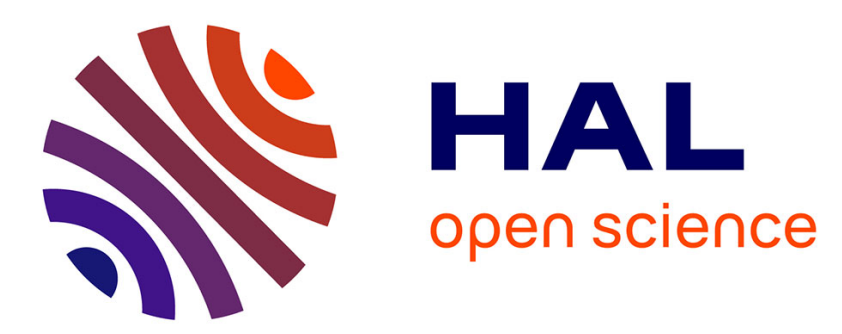

\title{
Magnetic properties of micrometeorites
}

\author{
C. Suavet, J. Gattacceca, P. Rochette, N. Perchiazzi, L. Folco, J. Duprat, R.P. \\ Harvey
}

\section{To cite this version:}

C. Suavet, J. Gattacceca, P. Rochette, N. Perchiazzi, L. Folco, et al.. Magnetic properties of micrometeorites. Journal of Geophysical Research: Solid Earth, 2009, 114, pp.B04102. 10.1029/2008JB005831 . in2p3-00684671

\section{HAL Id: in2p3-00684671 https://hal.in2p3.fr/in2p3-00684671}

Submitted on 29 Oct 2021

HAL is a multi-disciplinary open access archive for the deposit and dissemination of scientific research documents, whether they are published or not. The documents may come from teaching and research institutions in France or abroad, or from public or private research centers
L'archive ouverte pluridisciplinaire HAL, est destinée au dépôt et à la diffusion de documents scientifiques de niveau recherche, publiés ou non, émanant des établissements d'enseignement et de recherche français ou étrangers, des laboratoires publics ou privés. 


\title{
Magnetic properties of micrometeorites
}

\author{
C. Suavet, ${ }^{1}$ J. Gattacceca, ${ }^{1}$ P. Rochette, ${ }^{1}$ N. Perchiazzi, ${ }^{2}$ L. Folco, ${ }^{3}$ J. Duprat,${ }^{4}$ \\ and R. P. Harvey ${ }^{5}$ \\ Received 28 May 2008; revised 14 December 2008; accepted 29 January 2009; published 4 April 2009.
}

[1] Most micrometeorites are strongly magnetic: the signal of a single micrometeorite may exceed the signal of a weakly magnetized standard sediment sample. Micrometeorites contain abundant magnetite, mostly produced by high-temperature oxidation during atmospheric entry. In this study, we carried out measurements on 520 micrometeorites (505 melted cosmic spherules, 6 partially melted scoriaceous micrometeorites, and 9 unmelted micrometeorites). The natural remanent magnetization and the saturation isothermal remanent magnetization have been measured, followed by alternating field or thermal stepwise demagnetization. The natural remanent magnetization is in the range of $0.4-300 \mathrm{~A} / \mathrm{m}$ for cosmic spherules; it is a stable thermal remanent magnetization acquired by quenching in the Earth's magnetic field. The range is $3.8-16 \mathrm{~A} / \mathrm{m}$ for scoriaceous micrometeorites and $78-525 \mathrm{~A} / \mathrm{m}$ for unmelted micrometeorites, which may have preserved a preatmospheric magnetization. The magnetic susceptibility is in the range of $0.005-2.9$ SI for cosmic spherules and is in the range of $0.06-0.12$ SI for scoriaceous and unmelted micrometeorites. Temperature-dependent susceptibility analyses and thermal demagnetization indicate that magnetite is cation substituted in cosmic spherules.

Different populations of magnetite grains may have different degrees of cation substitution within a single micrometeorite. Anisotropy of magnetic susceptibility measurements indicates that micrometeorites are strongly anisotropic (anisotropy degree $>15 \%$ ) and that most have oblate fabrics consistent with the parallel habit of magnetite in barred olivine cosmic spherules.

Citation: Suavet, C., J. Gattacceca, P. Rochette, N. Perchiazzi, L. Folco, J. Duprat, and R. P. Harvey (2009), Magnetic properties of micrometeorites, J. Geophys. Res., 114, B04102, doi:10.1029/2008JB005831.

\section{Introduction}

[2] Micrometeorites (MMs) are terrestrially collected extraterrestrial particles smaller than about two millimeters. They constitute the main part of the mass flux of extraterrestrial matter accreted on Earth [Love and Brownlee, 1993; Taylor et al., 1998]. MMs have been found in deep-sea sediments, in seasonal lakes in Greenland, in Antarctic eolian sedimentary traps, ice and snow, and in continental sands (see Taylor and Lever [2001] for a review). Extraterrestrial matter is usually rich in iron (on average $20 \mathrm{wt} \%$ and up to $95 \%$ ). In space, the major iron-rich phases are $\mathrm{Fe}-\mathrm{Ni}$ alloys, iron sulfides and magnetite [e.g., Rochette et al., 2008a]. Petrographic studies of MMs have shown that substituted magnetite is abundantly produced by atmospheric high-temperature oxidation of the primary iron bearing phases (metal, sulfide, olivine, and pyroxene) [Love and Brownlee, 1991; Robin et al., 1992; Toppani et al., 2001;

\footnotetext{
${ }^{1}$ CEREGE, Aix-Marseille Université, CNRS, Aix-en-Provence, France. ${ }^{2}$ Dipartimento di Scienze della Terra, Università di Pisa, Pisa, Italy.

${ }^{3}$ Museo Nazionale dell'Antartide, Universit di Siena, Siena, Italy.

${ }^{4}$ CSNSM, Orsay, France.

${ }^{5}$ Department of Geological Sciences, Case Western Reserve University, Cleveland, Ohio, USA.
}

Copyright 2009 by the American Geophysical Union. 0148-0227/09/2008JB005831\$09.00
Toppani and Libourel, 2003; Genge et al., 2008]. Depending on the amount of melting and oxidation, most to all of the primary reduced iron-bearing phases will be transformed into magnetite, although relics of metal and sulfides are sometimes described in MMs. Melting occurs above a critical size of $\sim 100 \mu \mathrm{m}$, but unmelted to partially melted larger grains can be observed. Fully melted MMs are called cosmic spherules (CSs) owing to their spherical/ellipsoidal shape. Partially melted MMs have scoriaceous textures (ScMMs). The smallest particles experience little melting during atmospheric entry (unmelted fine-grained MMs (FgMMs) and coarse-grained MMs (CgMMs)). In this study, we measured the magnetic properties of $506 \mathrm{MM}$ from different locations in Antarctica (490 CSs, $6 \mathrm{ScMMs}$, 7 FgMMs and 2 CgMMs), and 14 CSs from other origins (Greenland lake sediments and Pacific Ocean sediments). This is the first study of this kind, besides the measurement of 14 Iron-type cosmic spherules by Marfaing et al. [2008]. Owing to their continuous influx, MMs are a minor constituent of every surface material on Earth. The study of the magnetization and magnetic susceptibility distributions of MMs allowed Suavet et al. [2008] to estimate their potential contribution to the magnetic properties of sediments. The study of the magnetization of unmelted micrometeorites is also important to decipher potential preatmospheric magnetizations and to understand and 
quantify the processes by which extraterrestrial materials acquired remanence in the Solar System.

\section{Samples: Origin and Preparation}

[3] In order to assess possible effects of terrestrial weathering, we analyzed samples with different terrestrial residence times (the time elapsed since the MMs fell on Earth) ranging from tens of years to hundreds of thousands of years, and different residence conditions on Earth. The studied collections are as follows:

[4] 1. MMs found in natural traps at the top of Frontier Mountain (204 CSs) and Miller Butte (180 CSs and 4 ScMMs), in the Transantarctic Mountains, Victoria Land, Antarctica [Rochette et al., 2008b]. The samples were collected during the 2003 and 2006 PNRA (Programma Nazionale di Ricerche in Antartide) expeditions. These traps are believed to have sampled direct cosmic infall for several hundreds of thousands of years, as evidenced by the presence of $\sim 0.8$ Ma old microtektites [Folco et al., 2008].

[5] 2. We analyzed $82 \mathrm{CSs}$ and $1 \mathrm{ScMM}$ that were extracted from eolian sediment traps on the crests of moraines of the Walcott Névé, Transantarctic Mountains, Antarctica [Harvey and Maurette, 1991]. These MMs were incorporated into snow that was compacted into firn and ice. They were transported in a glacial flow before it was ablated. The entrained MMs were then transported by wind and deposited in sedimentary traps on the crests of moraines.

[6] 3. 17 studied MMs (16 CSs and 1 ScMM) were sampled from surface snow of Dome C, Antarctica: these samples are part of the CONCORDIA collection [Duprat et al., 2007]. The studied samples were extracted from the snow layers corresponding to years 1970 to 1980 .

[7] 4. We analyzed 8 CSs, 7 FgMMs and 2 CgMMs found in the Cap Prudhomme blue ice fields, on the East Antarctic ice sheet [Maurette et al., 1991]. This collection was obtained by melting hundreds of tons of blue ice. The MM were carried by the ice flow prior to their collection.

[8] 5. 11 CSs from Greenland seasonal lake sediments [Maurette et al., 1986] were analyzed.

[9] 6. 3 CSs were extracted from Pacific deep-sea sediments that are curated at the Lamont-Doherty Earth Observatory Deep-Sea Sample Repository. The sediment samples were chosen from low sedimentation rate environments $(0.08-0.2 \mathrm{~cm} / \mathrm{ka}$ ) of cores $5-38$ (Eocene zeolitic clay, North East Pacific, $38^{\circ} 42.12^{\prime} \mathrm{N}, 140^{\circ} 21.27^{\prime} \mathrm{W}$ ) [McManus et al., 1970] and 16-160 (Pleistocene zeolitic clay, from the west flank of the East Pacific Rise, $11^{\circ} 42.27^{\prime} \mathrm{N}$, $130^{\circ} 55.81^{\prime} \mathrm{W}$ ) [van Andel et al., 1973].

[10] For Frontier Mountain, Miller Butte, Walcott Névé and Pacific Ocean sediments, the MMs were extracted using different techniques depending on the original sample, after wet sieving at 200, 400, $800 \mu \mathrm{m}(400,800 \mu \mathrm{m}$ for Miller Butte). The fractions were separated using heavy liquids (methylene iodide, $\rho=3300 \mathrm{~kg} / \mathrm{m}^{3}$ ) and the light fraction was further sorted by magnetic extraction (which therefore excluded this fraction from natural remanent magnetization (NRM) analyses). The Miller Butte sample was the only one that did not require further separation after sieving owing to its high concentration of cosmic particles. Potential extraterrestrial particles were handpicked under a binocular microscope. Selection was made according to the morphology of the particles.

\section{Analytical Methods}

[11] Micrographs of the MMs were taken at CEREGE (Aix-en-Provence, France) with a scanning electron microscope (SEM, Hitachi S-3000N) using a $24 \mathrm{kV}$ accelerating voltage, either with secondary electrons (SE) or backscattered electrons (BSE). A number of physicochemical analyses were performed on the samples. The largest MMs were directly weighed using a micro balance $(1 \mu \mathrm{g}$ precision). Bulk chemical analyses were made using a Micro X-Ray Fluorescence (XRF) microscope (Horiba XGT-5000 at CEREGE, accelerating voltage $30 \mathrm{kV}$ ). The analyses are performed with a $100 \mu \mathrm{m}$ or $10 \mu \mathrm{m}$ diameter beam. Beam penetration is of the order of $100 \mu \mathrm{m}$, so the analysis is an average of the weathered outer layer and the pristine inner material. The XRF instrument is calibrated for a semi-infinite medium, therefore these analyses are semiquantitative. All magnetic measurements were performed at CEREGE. The NRM and saturation isothermal remanent magnetization (sIRM), which was imparted in an inducing field of $1 \mathrm{~T}$, were measured on MMs with a $2 \mathrm{G}$ Enterprises DC Squid cryogenic magnetometer. The magnetic moment of the sample holder is in the range of $7.9 \times 10^{-12}-1.1 \times$ $10^{-10} \mathrm{Am}^{2}$, with a median value of $3.2 \times 10^{-11} \mathrm{Am}^{2}$. After saturation, the IRM of the sample holder is in the range of $4.32 \times 10^{-10}-1.9 \times 10^{-9} \mathrm{Am}^{2}$, with a median value of $6.9 \times 10^{-10} \mathrm{Am}^{2}$. The reproducibility is within a range of $\pm 2.8 \times 10^{-12}-1.2 \times 10^{-11} \mathrm{Am}^{2}$, with a median value of $\pm 5.7 \times 10^{-12} \mathrm{Am}^{2}$. Some samples were subjected to stepwise alternating field demagnetization of NRM and sIRM (at 2, 4, 6, 8, 10, 15, 20, 25, 30, 40, 50, 60, 80, and $100 \mathrm{mT}$ ), or thermal demagnetization of SIRM (at 200, $250,300,380,400,415,480,500,530,560$ and $\left.580^{\circ} \mathrm{C}\right)$. For thermal demagnetization, samples were wrapped in aluminum foil after saturation, and during the whole process of heating and measurement of moment. The magnetic moment of the aluminum foil is $9 \pm 5 \times 10^{-11} \mathrm{Am}^{2}$. Hysteresis parameters were measured with a Princeton Measurements Corporation (PMC) Alternating Field Magnetometer (AGM) with a peak field of $0.3 \mathrm{~T}$ or $0.5 \mathrm{~T}$ for the hysteresis loop (noise level of $\sim 10^{-11} \mathrm{Am}^{2}$ ). A systematic correction was made for the sample holder (measured at least once per measurement session). However, the effect of this correction on hysteresis parameters values is small ( \pm 0.02 on the ratio of saturation remanent magnetization and saturation magnetization, $\pm 0.3 \mathrm{mT}$ on the value of the coercive field). Some of the largest samples (FRO1, FRO2 146-158, FRO3 7-22, see Data Set S1 in the auxiliary material) ${ }^{1}$ were measured with a PMC Vibrating Sample Magnetometer (VSM) with a peak field of $0.5 \mathrm{~T}$ (noise level of $\sim 10^{-9} \mathrm{Am}^{2}$ ). ${ }^{1}$ Magnetic susceptibility was measured with a KLY 2 Kappabridge (noise level of $\sim 5 \times$ $10^{-13} \mathrm{~m}^{3}$ ) or MFK1-FA magnetic susceptibility meter for some samples (noise level of $\sim 3 \times 10^{-13} \mathrm{~m}^{3}$ ). The sample holder was measured frequently (every $2-3$ samples) to cancel the effect of the instrumental drift. We measured

\footnotetext{
${ }^{1}$ Auxiliary material data sets are available at $\mathrm{ftp}: / / \mathrm{ftp}$.agu.org/apend/jb/ 2008jb005831. Other auxiliary material files are in the HTML.
} 
sample 05-13-01 (total magnetic susceptibility $=5.4 \times$ $10^{-12} \mathrm{~m}^{3}$ ) with the MFK1-FA meter at different times during the measurement session (20 measurements) to evaluate reproducibility. The standard deviation of these measurements is $\sigma=1.6 \times 10^{-13} \mathrm{~m}^{3}$. The anisotropy of magnetic susceptibility was measured on the largest samples using the MFK1-FA meter. Temperature-dependent magnetic susceptibility analyses were performed in an argon atmosphere on 6 samples using the MFK1-FA meter equipped with a CS3 furnace (a furnace correction was made on the data). After these analyses, MMs from Frontier Mountain, Miller Butte, Walcott Névé and the Pacific Ocean were embedded in epoxy and polished. SEM images of the sections were taken at CEREGE (Hitachi S-3000N, $24 \mathrm{kV}$ acceleration voltage, BSE). Wavelength dispersive spectrometry (WDS) chemical analyses (Cameca SX 50, accelerating voltage $15 \mathrm{kV}$ ) were performed at Istituto di Geoscienze e Georisorse Padova, Italy, on polished sections of MM samples from Frontier Mountain and Walcott Névé, and at Université Pierre et Marie Curie, Paris, France, on polished sections of MM samples from Miller Butte. Two CSs, representative of iron and stony spherules, were studied through synchrotron X-Ray diffraction data, collected at BM8-GILDA beamline, ESRF, Grenoble. A monochromatic beam $(\lambda=0.6904 \AA$ for the stony particle and $\lambda=0.7761 \AA$ for the iron particle, calibrated against X-Ray absorption of pure metal foils) was used and the diffractions were collected with a Fuji Imaging-Plate (IP) detector. The beam dimension on the sample was $0.2 \times$ $0.2 \mathrm{~mm}$. The sample to detector distance and the image plate tilt were calibrated with X-Ray powder diffraction of standard $\mathrm{LaB}_{6}$ (NIST-SRM 660a). Data were collected up a $d$-space resolution of $\sim 0.8 \AA$ for both data sets, and reduced with the Fit2D software [Hammersley, 1997]. Phase identification was performed through the EVA (Bruker-AXS) software. A Rietveld study was performed through the TOPAS software (A. A. Coelho, TOPAS-ACADEMIC, 2004) to determine the relative abundances of the phases.

\section{Characterization of Micrometeorites}

[12] Chemical analyses confirm that all spherules in our samples are of extraterrestrial origin. Such origin (with respect to impact, volcanic or anthropogenic spherules) is evidenced by the presence of $\mathrm{Ni}$ and $\mathrm{Cr}$, the abundance of $\mathrm{Mg}(\mathrm{Mg} \gg \mathrm{Al}$, and $\mathrm{Mg} \approx \mathrm{Si})$, and the very low level of $\mathrm{Ti}$, $\mathrm{K}$, Al with respect to terrestrial matter. For unmelted angular material, morphology is less distinctive and the chemical analysis was necessary to distinguish between terrestrial (e.g., tephra) and extraterrestrial particles. Figure 1 presents a Mg-Si-Fe (atoms) ternary plot of the Antarctic CSs we have studied, with the compositional range of Greenland,

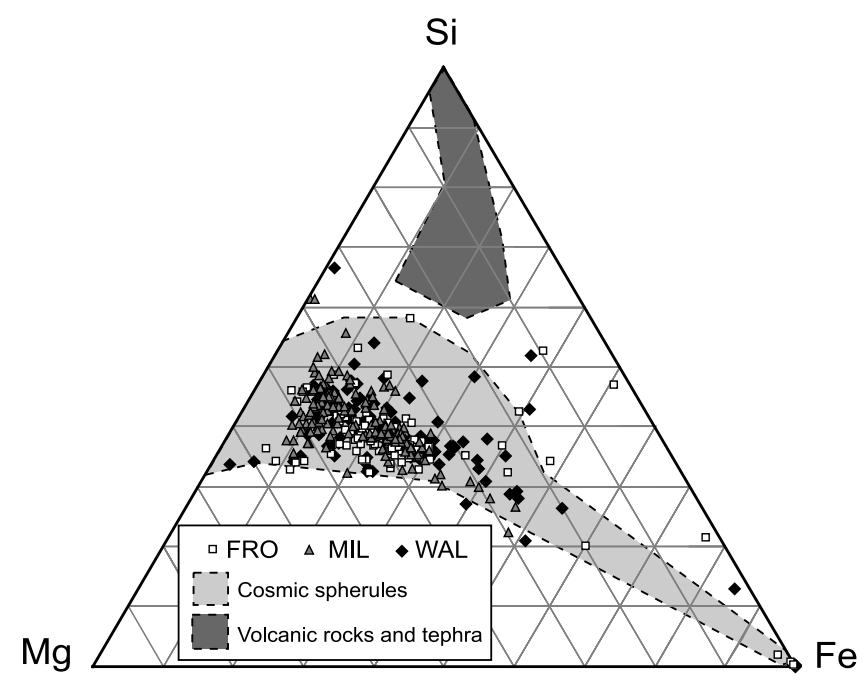

Figure 1. $\mathrm{Mg}-\mathrm{Si}-\mathrm{Fe}$ (atoms) ternary diagram presenting the wavelength dispersive spectrometry chemical analyses results for Frontier Mountain, Miller Butte, and Walcott Névé micrometeorites. Local volcanic rocks [LeMasurier and Thomson, 1990] and tephra [Curzio et al., 2008] have a different compositional range, which allows distinction between extraterrestrial and terrestrial particles. Particles outside the compositional range of cosmic spherules [Taylor et al., 2000] have been identified as micrometeorites on the basis of their texture.

other Antarctic and deep sea CSs [Taylor et al., 2000]. This range is distinct from that of local volcanic rocks [LeMasurier and Thomson, 1990] and tephra [Curzio et al., 2008]. Very minor fly ashes may be emitted in Antarctica from the activity of permanent stations (from welding, waste incineration, vehicles) or large ships, but our major Antarctic sampling site (TAM) was at $>100 \mathrm{~km}$ from the coast or any permanent station. In the other sites care was taken to avoid pollution from the surface layers, and sampling sites were upwind from Antarctic stations. Despite the highaltitude injection of volcanic tephra from South American volcanoes in Antarctica, Basile et al. [2001] have shown that the maximum diameter for these particles is $50 \mu \mathrm{m}$. Therefore, the presence of fly ashes in our samples is highly improbable in the size range we studied. Characteristic surface features of MMs can be identified in whole particle SEM images (Figure 2, samples CSa-CSe). The volume has been estimated using whole particles SEM images, assuming that the semiminor axes are equal for spherules, or using a different geometry for particles with a noneven shape. SEM images of the polished sections enabled classification of the MMs into different categories. The main factor determining

Figure 2. Scanning electron microscope backscattered electron images of polished sections (except for the whole spherules when specified as secondary electron (SE)) of cosmic spherules. CSa is barred olivine cosmic spherule FRO2-007 (SE) with visible bars, CSb is cryptocrystalline cosmic spherule FRO2-006 (SE) with knobbly protrusions, CSc is porphyritic olivine cosmic spherule 03-40-17 (SE) with olivine microphenocrysts, CSd is I-type cosmic spherule FRO2-090 (SE), and CSe is G-type cosmic spherule FRO2-071 (SE). Barred olivine (BO) cosmic spherules. BOa is WAL-015, BOb is FRO2-013, BOc is FRO2-037, BOd is FRO2-113, and BOe is WAL-038. Porphyritic olivine (PO) cosmic spherules. POa is WAL-079, POb is FRO2-085, POc is FRO2-092, POd is FRO2-115, and POe is FRO2-075. Cryptocrystalline (CC) cosmic spherules. CCa is WAL-060, CCb is WAL-011, and CCc is WAL-119. V-type (V) cosmic spherules. Va is 03-40-06 and Vb is MIL-135. I-type (I) cosmic spherules. Ia is FRO2-028, Ib is FRO2-026, Ic is WAL-009, Id is FRO2-090, and Ie is FRO2-016. G-type (G) cosmic spherules. Ga is MIL-073, Gb is MIL-087, Gc is FRO2-071, Gd is WAL-059, and Ge is FRO2-039. 


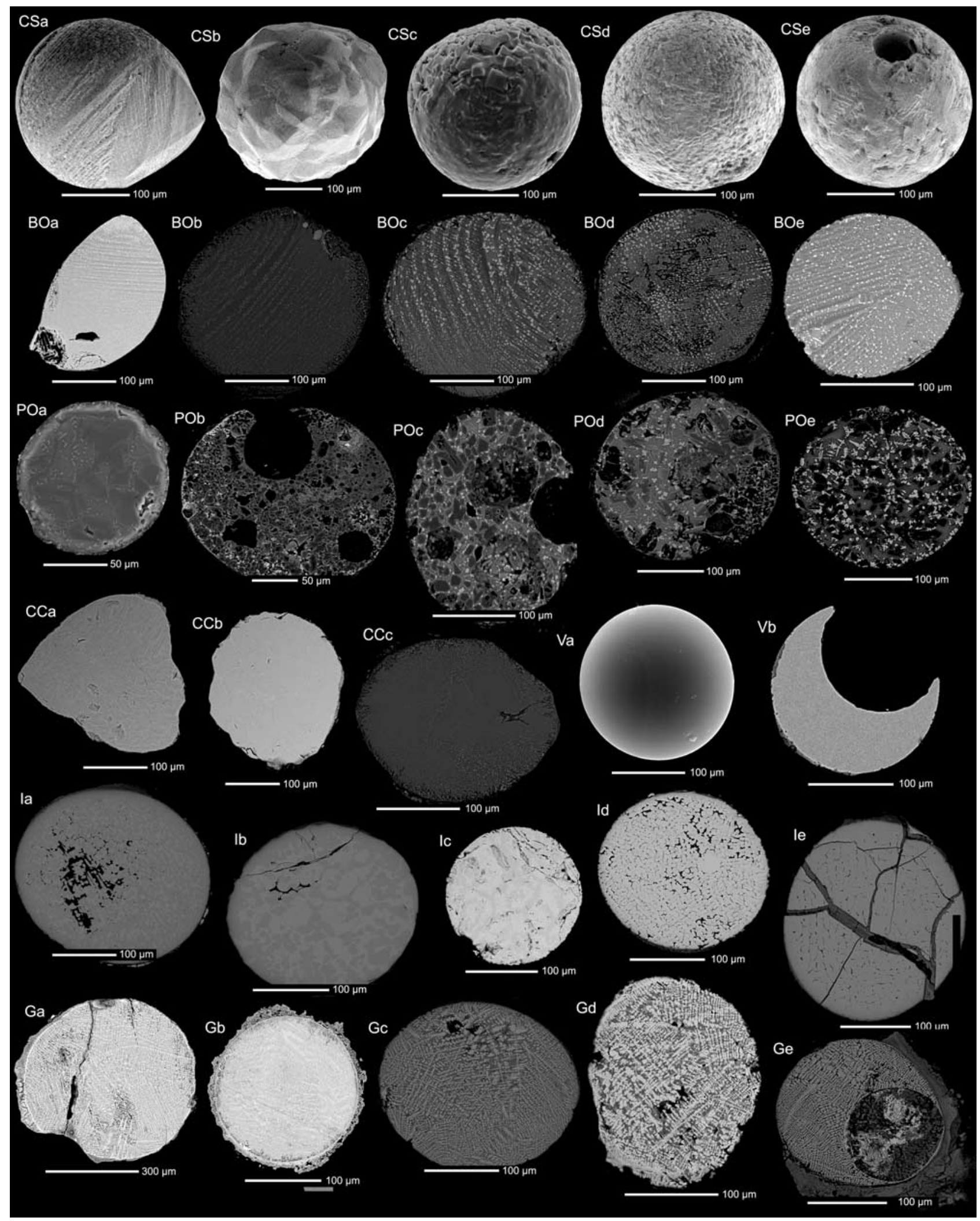

Figure 2 


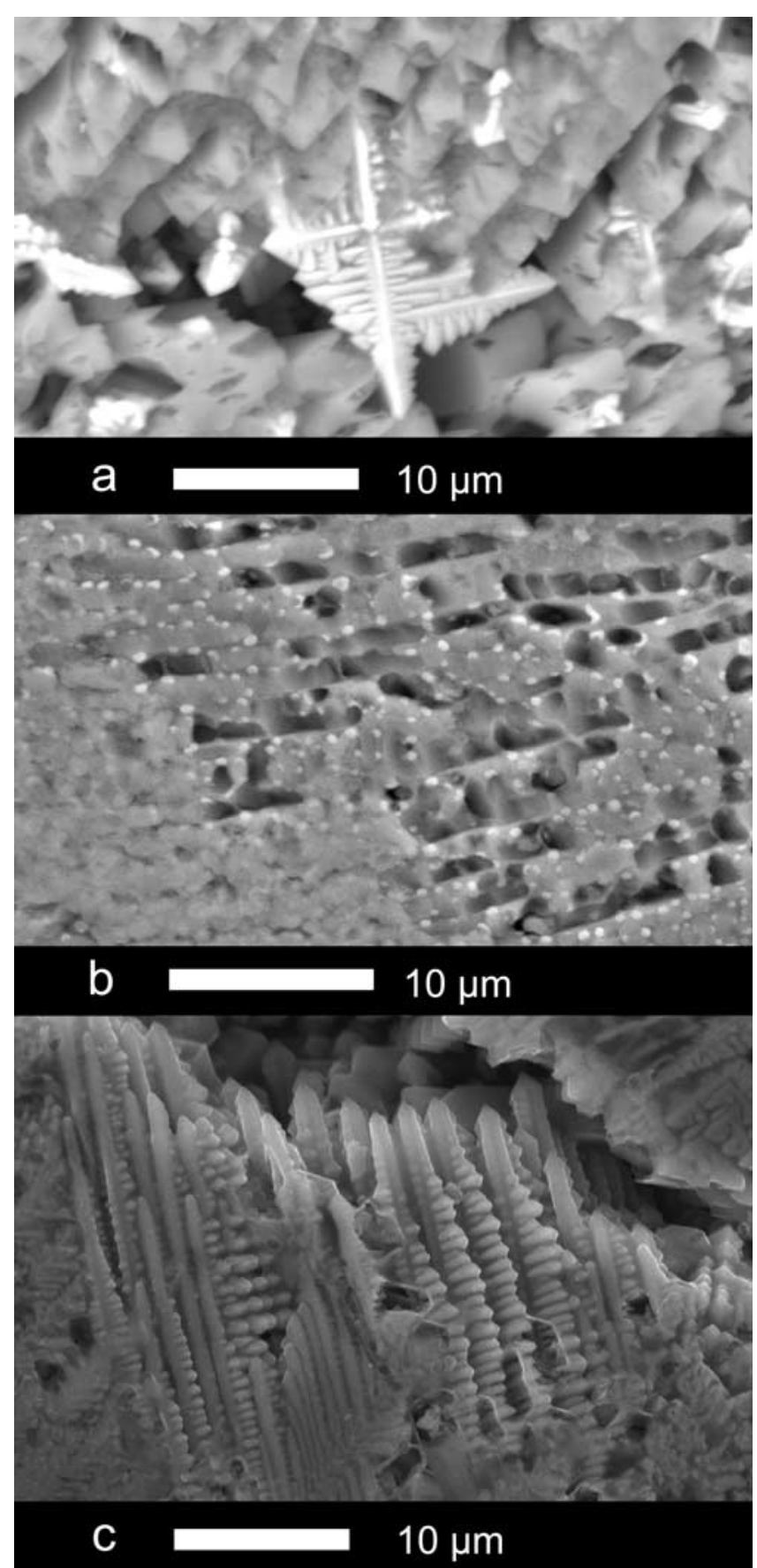

Figure 3. Close up scanning electron microscope backscattered electron images of magnetite grains on the surface of barred olivine cosmic spherules. (a) Magnetite dendrite. (b) Small magnetite grains $(<1 \mu \mathrm{m})$. (c) Large magnetite dendrites $(>10 \mu \mathrm{m})$.

the texture of micrometeorites is the extent of thermal reprocessing during atmospheric entry [Genge et al., 2008].

[13] The most common CSs are S-type (stony). Their composition is broadly chondritic [Genge et al., 2008]. They are dominated by olivine microphenocrysts, silicate glass and magnetite and/or chromite, and they can also contain relict grains that survived atmospheric entry. Depending on the texture, S-type CSs can be subdivided into subclasses. Barred olivine CSs (BO) are dominated by parallel growth olivine within a glassy mesostasis with magnetite (Figure 2, samples BOa-BOe). Porphyritic olivine CSs (PO) are dominated by olivine microphenocrysts within a glassy mesostasis with accessory magnetite/chromite, and relict olivine grains are commonly found (Figure 2, samples $\mathrm{POa}-\mathrm{POe}$ ). Cryptocrystalline CSs (CC) contain micron to submicron olivine crystals and magnetite grains (Figure 2, samples $\mathrm{CCa}-\mathrm{CCc}$ ). V-type (glass) $\mathrm{CSs}$ do not contain olivine microphenocrysts (Figure 2, samples $\mathrm{Va}$ and $\mathrm{Vb}$ ). Figure 3 shows close up SEM images of magnetite grains at the surface of BO CSs. Dendrites of magnetite can have sizes up to a few tens of $\mu \mathrm{m}$, whereas the smallest grains are $<1 \mu \mathrm{m}$.

[14] I-type (iron) CSs contain iron oxides wüstite and magnetite [Genge et al., 2008] (Figure 2, samples Ia-Ie). In rare cases metal cores have been described, but none were observed in this study or in that of Marfaing et al. [2008].

[15] G-type CSs are dominated by dendritic magnetite within a mesostasis of silicate glass [Genge et al., 2008] (Figure 2, samples $\mathrm{Ga}-\mathrm{Ge}$ ).

[16] ScMMs are highly vesicular particles consisting mainly of microporphyritic olivine crystals in a silicate glass (Figure 4, samples SCa-SCe), often containing crystal and/or lithic relics. They are surrounded by a magnetite rim that is produced during the atmospheric entry.

[17] The most heated unmelted MMs also have a magnetite rim. Fine-grained micrometeorites (FgMMs) (Figure 4, samples FGa-FGd) are dominated by a groundmass similar to the fine-grained matrices of chondritic meteorites, whereas coarse-grained micrometeorites (CgMMs) (Figure 4, samples $\mathrm{CGa}-\mathrm{CGb}$ ) are dominated by anhydrous silicate grains larger than $\sim 1 \mu \mathrm{m}$.

[18] In order to check the presence of magnetic phases other than magnetite, one I-type CS and one S-type CS were studied through synchrotron X-Ray diffraction (Figure 5). Phase identification shows that the I-type particle is made of magnetite and minor wüstite, whereas the S-type particle is constituted of forsterite and minor magnetite. The possible presence of other magnetic phases was carefully checked but none were revealed. A Rietveld study (see Figure S1 in the auxiliary material) allowed us to determine the relative abundance of the identified phases, namely, not accounting for the presence of a possible amorphous component: the I-type spherule has a magnetite to wüstite ratio of $89: 11$, whereas the S-type particle has a forsterite to magnetite ratio of 97:3. The scrutiny of refined cell parameters allows us to get information on the crystal chemistry of the constituting phases. For the I-type particle, refined cell parameters for magnetite and wüstite are respectively $a=8.404(1) \stackrel{\circ}{A}$ and $a=4.298(1) \stackrel{\circ}{A}$, which compare well with the literature data for these phases, indicating that both magnetite and wüstite are pure phases. For the S-type particle, the refined cell parameters for magnetite is $a=8.382(1) \AA$, which is smaller than the value for pure magnetite. This indicates substitution of magnetite, but the substitution degree and the substitute elements cannot be deduced from these measurements.

\section{Magnetic Properties}

[19] In order to characterize MMs in terms of magnetic mineralogy, we measured the "S ratio" $S_{-0.3}$ of 10 stony CS samples from Frontier Mountain: it is the IRM obtained 


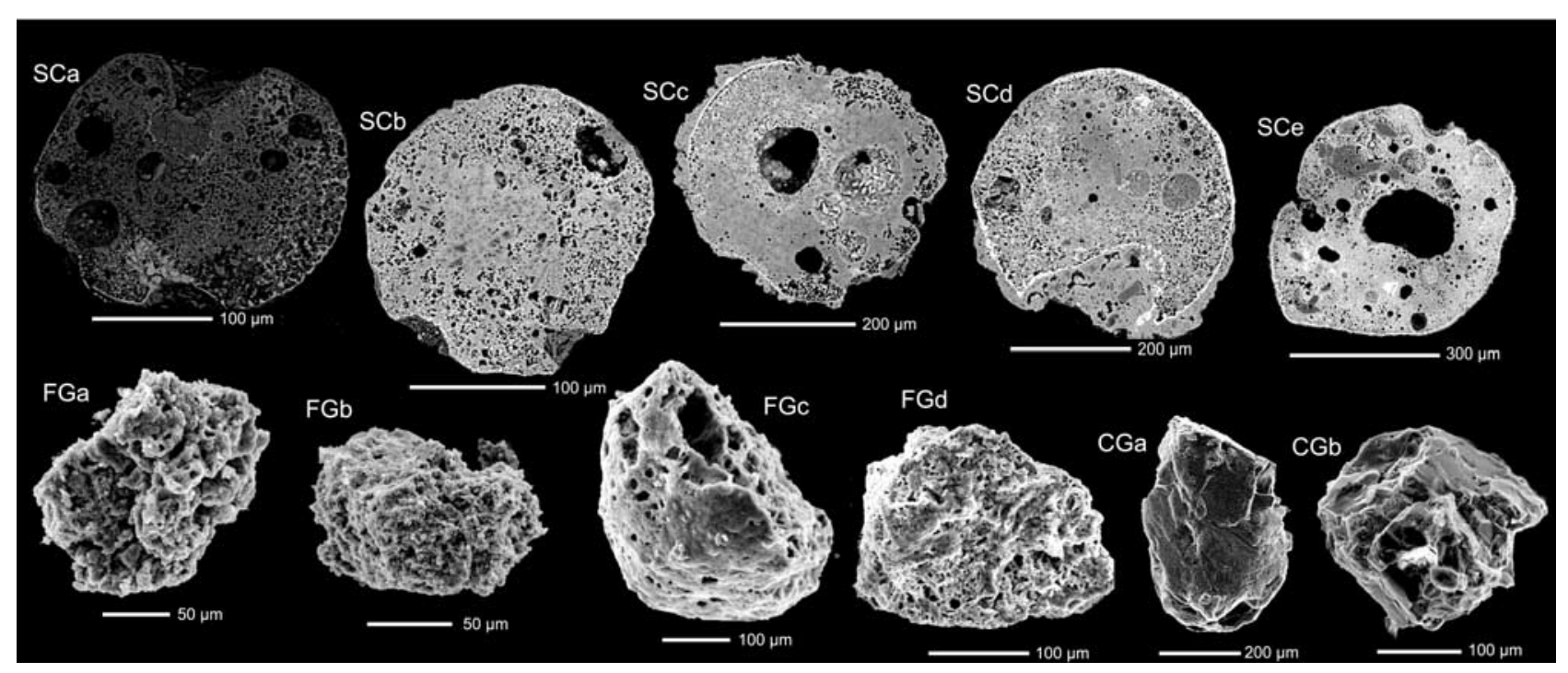

Figure 4. Scanning electron microscope backscattered electrons images of scoriaceous micrometeorites and secondary electron images of unmelted micrometeorites. Scoriaceous (SC) micrometeorites. SCa is FRO2-107, SCb is MIL-040, SCc is MIL-082, SCd is MIL-090, and SCe is MIL-144. Fine-grained (FG) unmelted micrometeorites. FGa is $05-37-02$, FGb is $05-37-19$, FGc is $05-37-10$, and FGd is $05-37-23$. Coarse-grained (CG) unmelted micrometeorites. CGa is $05-37-14$ and CGb is $05-37-22$.

after applying a $3 \mathrm{~T}$ field and then a back field of $-0.3 \mathrm{~T}$ normalized to the $3 \mathrm{~T}$ IRM. The $\mathrm{S}$ ratios are in the range $0.94-1.00$, with a mean value of 0.98 . Such high values are typical of magnetite.

[20] Temperature-dependent magnetic susceptibility analyses performed on 6 Miller Butte CSs (Figure 6) allow us to estimate Curie temperatures $\left(T_{c}\right)$. According to Petrovský and Kapièka [2006], the commonly used two-tangent method [Grommé et al., 1969] overestimates $T_{c}$ by up to a few tens of degrees. They recommend to define $T_{c}$ as the intersect of the linear fit to inverse susceptibility and the temperature axis, when linear behavior of inverse susceptibility is observed. We estimated $T_{c}$ with both methods (Table 1): the inverse susceptibility method yields values in the range of $517-$ $552^{\circ} \mathrm{C}$, whereas the two-tangent method yields values in the range of $500-585^{\circ} \mathrm{C}$. The Curie temperatures for $\mathrm{BO}$ samples MIL-036, MIL-051, MIL-127 are $\sim 60^{\circ} \mathrm{C}$ below the $580^{\circ} \mathrm{C}$ expected for pure magnetite [Dunlop and Özdemir, 2001], which indicates that magnetite in these samples contains impurities. WDS bulk analyses indicate the presence of $\mathrm{Ni}, \mathrm{Cr}$ and $\mathrm{Ti}$. These elements can be substituted for $\mathrm{Fe}$ in magnetite. Unfortunately, we could not measure single magnetite grains with the microprobe, but we observed that measurements averaged on magnetite grains and silicate surrounding minerals reveal higher concentrations of these elements than measurements on silicates. Robin et al. [1992] analyzed single magnetite grains in micrometeorites using a SEM with energy dispersive spectrometer: the range is $0-3 \%$ for $\mathrm{NiO}, 0-20 \%$ for $\mathrm{Cr}_{2} \mathrm{O}_{3}$ and $0-1 \%$ for $\mathrm{TiO}$. The Curie temperatures of BO samples MIL-118 and MIL-004, and G-type sample MIL- 073 are closer to $580^{\circ} \mathrm{C}$, which indicates that magnetite in these samples contains less impurities than for other samples. However, WDS bulk analyses do not reveal differences in the chemical composition of these samples.

[21] Thermal demagnetization of sIRM (Figure 7) measured on 13 CSs gives maximum blocking temperatures in
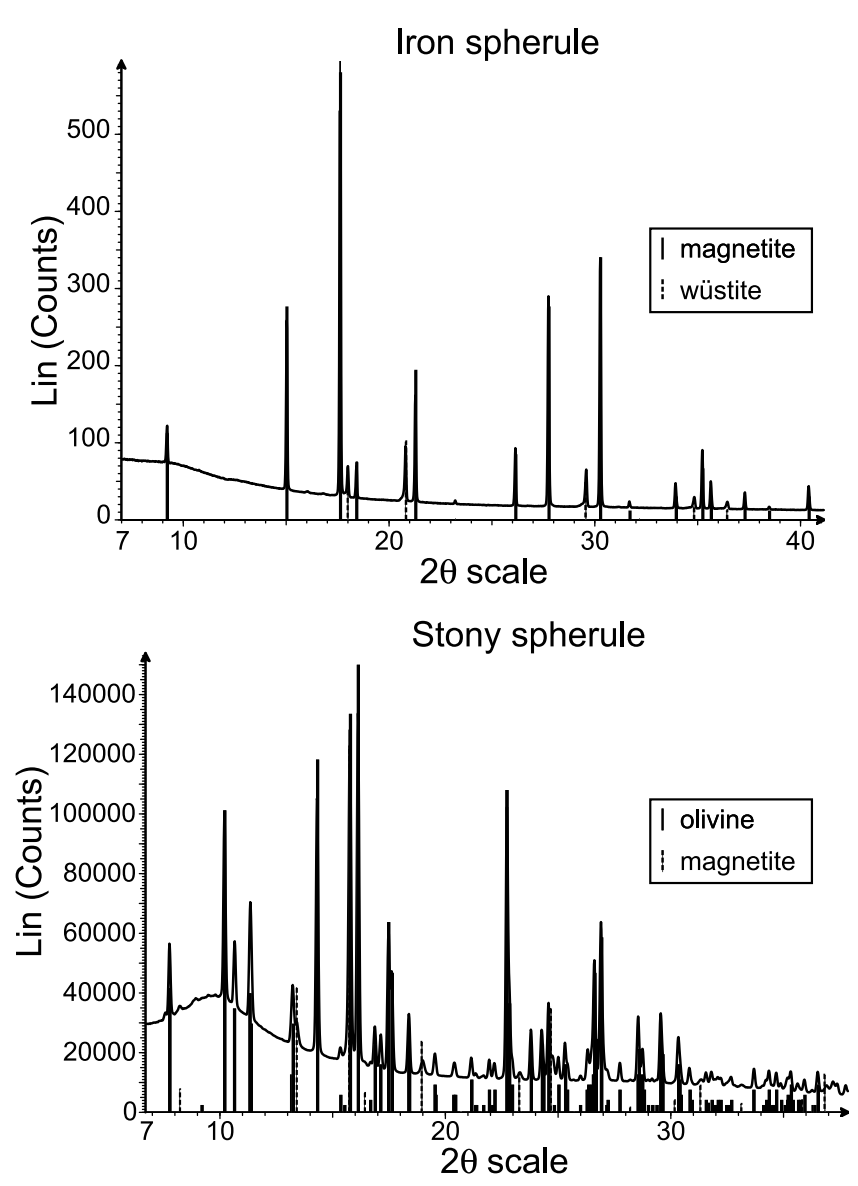

Figure 5. X-Ray diffraction pattern of iron and stony cosmic spherules, with superimposed patterns of diffracting phases: magnetite and wüstite. 


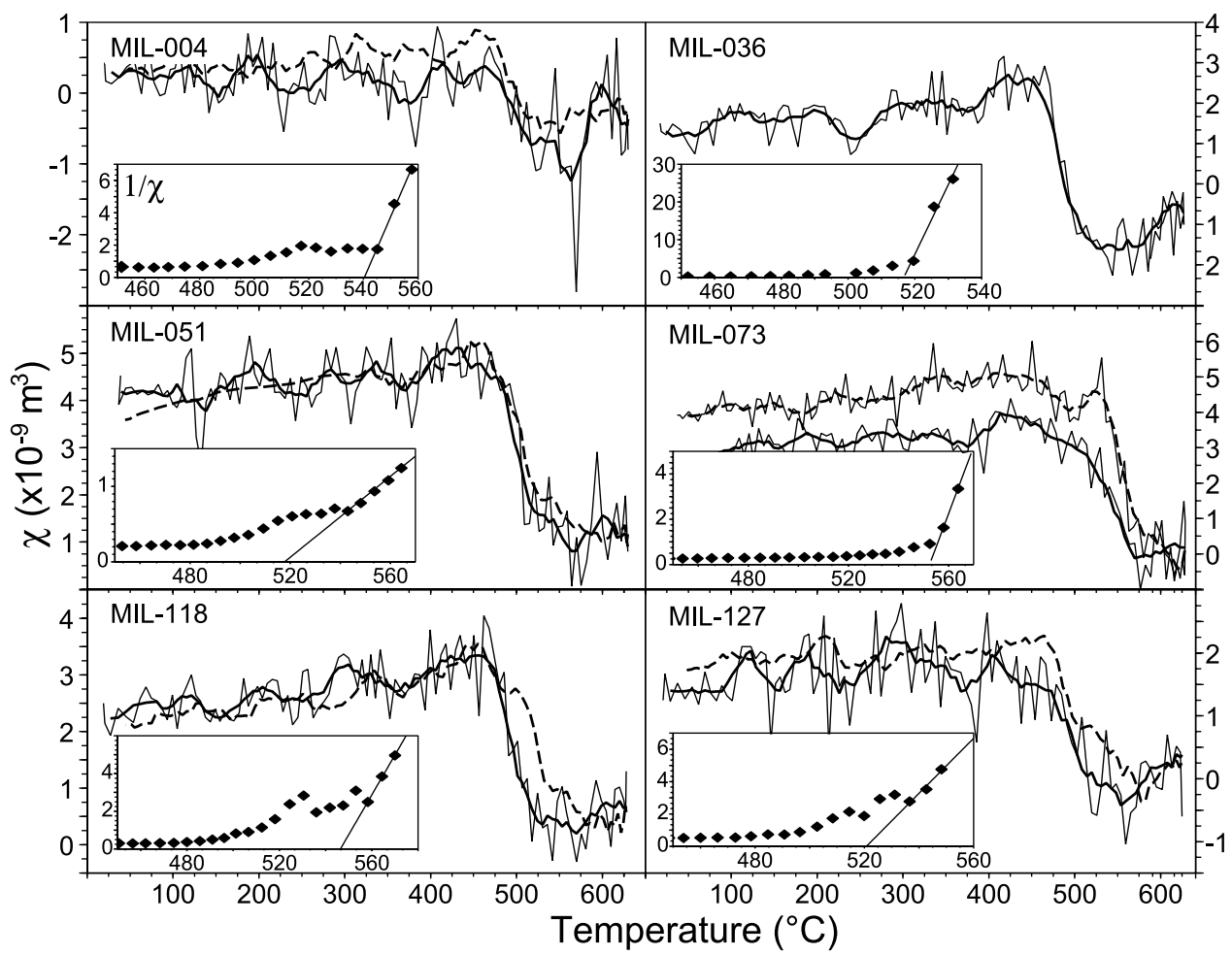

Figure 6. Temperature-dependent magnetic susceptibility $(\chi)$ analyses for selected micrometeorite samples. The Curie temperatures are estimated with the inverse susceptibility $(1 / \chi$, compare inset) method [Petrovský and Kapièka, 2006]. The thick solid curve is a smoothed curve (moving average of 5 measurements) of the heating path. The dashed curve is smoothed curve of the cooling path (the cooling path was not measured for sample MIL-036).

the range of $555-585^{\circ} \mathrm{C}$ (Table 1). These temperatures are significantly higher than estimated $T_{c}$ values. BO sample MIL-004 is the only particle for which both analyses were made. Its $T_{c}$ is $\sim 540^{\circ} \mathrm{C}$ (Table 1), and its maximum blocking temperature is $566 \pm 5^{\circ} \mathrm{C}$ (Table 1). Most of the remanence is carried by small magnetite grains, whereas larger magnetite grains dominate the magnetic susceptibility (which was used to estimate $T_{c}$ ). The difference found between thermal demagnetization and temperaturedependent susceptibility analyses may indicate the presence

Table 1. Temperature-Dependent Magnetic Susceptibility Analyses and Thermal Demagnetization of sIRM Results ${ }^{\mathrm{a}}$

\begin{tabular}{|c|c|c|c|c|c|c|c|c|c|c|c|c|c|c|c|}
\hline Sample & Type $^{\text {b }}$ & $\mathrm{Mg}$ & $\mathrm{Al}$ & $\mathrm{Si}$ & $\mathrm{Ca}$ & $\mathrm{Ti}$ & $\mathrm{Cr}$ & $\mathrm{Mn}$ & $\mathrm{Fe}$ & $\mathrm{Ni}$ & $\mathrm{O}$ & Sum & $T_{c P}$ & $T_{c 2 t}$ & MBT \\
\hline MIL-004 & PO & 14.99 & 1.81 & 15.11 & 0.39 & 0.03 & 0.57 & 0.06 & 8.82 & 0.03 & 58.16 & 99.98 & 540 & $500-550$ & $566 \pm 5$ \\
\hline MIL-013 & $\mathrm{S}$ & NA & NA & NA & NA & NA & NA & NA & NA & NA & NA & NA & & & $560 \pm 5$ \\
\hline MIL-019 & V & 16.71 & 1.29 & 16.30 & 0.99 & 0.03 & 0.04 & 0.13 & 6.05 & 0.00 & 58.49 & 100.02 & & & $564 \pm 5$ \\
\hline MIL-020 & $\mathrm{BO}$ & 15.48 & 1.49 & 14.20 & 1.03 & 0.06 & 0.10 & 0.05 & 9.88 & 0.16 & 57.53 & 99.97 & & & $565 \pm 5$ \\
\hline MIL-023 & $\mathrm{PO}$ & 19.25 & 0.61 & 14.53 & 0.47 & 0.01 & 0.09 & 0.07 & 7.46 & 0.05 & 57.44 & 99.96 & & & $568 \pm 5$ \\
\hline MIL-024 & $\mathrm{BO}$ & 16.01 & 0.90 & 14.59 & 1.23 & 0.04 & 0.03 & 0.08 & 9.55 & 0.00 & 57.55 & 99.98 & & & $569 \pm 5$ \\
\hline MIL-027 & $\mathrm{BO}$ & 16.49 & 1.36 & 16.20 & 1.22 & 0.02 & 0.10 & 0.09 & 6.01 & 0.02 & 58.48 & 100.00 & & & $565 \pm 5$ \\
\hline MIL-036 & $\mathrm{BO}$ & 11.85 & 2.28 & 17.49 & 1.39 & 0.03 & 0.07 & 0.10 & 7.33 & 0.02 & 59.30 & 99.85 & 517 & $510-550$ & \\
\hline MIL-044 & $\mathrm{BO}$ & 15.28 & 1.40 & 16.49 & 0.20 & 0.02 & 0.11 & 0.08 & 7.75 & 0.00 & 58.63 & 99.97 & & & $562 \pm 5$ \\
\hline MIL-051 & $\mathrm{BO}$ & 15.87 & 1.24 & 14.23 & 0.69 & 0.05 & 0.19 & 0.09 & 9.62 & 0.49 & 57.49 & 99.96 & 518 & $510-550$ & \\
\hline MIL-073 & $\mathrm{G}$ & 11.40 & 0.66 & 11.34 & 0.40 & 0.03 & 0.11 & 0.02 & 19.98 & 0.01 & 55.91 & 99.87 & 552 & $575-585$ & \\
\hline MIL-118 & $\mathrm{BO}$ & 15.17 & 1.54 & 15.08 & 0.67 & 0.05 & 0.09 & 0.09 & 9.08 & 0.25 & 57.97 & 99.97 & 546 & $520-560$ & \\
\hline MIL-120 & $\mathrm{BO}$ & 13.95 & 1.56 & 14.54 & 1.11 & 0.05 & 0.07 & 0.07 & 10.89 & 0.07 & 57.69 & 99.99 & & & $580 \pm 5$ \\
\hline MIL-127 & $\mathrm{BO}$ & 13.34 & 1.47 & 13.84 & 1.45 & 0.04 & 0.19 & 0.11 & 11.72 & 0.47 & 57.35 & 99.98 & 521 & $525-575$ & \\
\hline MIL-157 & $\mathrm{CC}$ & 17.91 & 0.55 & 15.96 & 0.40 & 0.02 & 0.07 & 0.13 & 6.82 & 0.01 & 58.14 & 100.01 & & & $576 \pm 5$ \\
\hline MIL-158 & $\mathrm{BO}$ & 14.87 & 1.42 & 14.67 & 1.14 & 0.05 & 0.14 & 0.06 & 9.70 & 0.25 & 57.75 & 100.05 & & & $571 \pm 5$ \\
\hline MIL-160 & $\mathrm{BO}$ & 12.25 & 1.47 & 13.92 & 1.26 & 0.02 & 0.21 & 0.08 & 12.85 & 0.41 & 57.39 & 99.85 & & & $574 \pm 5$ \\
\hline MIL-161 & $\mathrm{CC}$ & 17.99 & 1.14 & 15.78 & 0.89 & 0.03 & 0.06 & 0.13 & 5.77 & 0.02 & 58.20 & 100.02 & & & $560 \pm 5$ \\
\hline
\end{tabular}

${ }^{a}$ Bulk chemical analyses were obtained by averaging wavelength dispersive spectrometry measurements on a $30 \times 20 \mu \mathrm{m}$ window. They are given in atom percentage. $T_{c P}$ is the Curie temperature (in ${ }^{\circ} \mathrm{C}$ ) obtained with inverse susceptibility method [Petrovský and Kapièka, 2006], $T_{c 2 t}$ is the Curie temperature (in ${ }^{\circ} \mathrm{C}$ ) obtained with the two tangent method [Grommé et al., 1969]. MBT is the maximum blocking temperature (in ${ }^{\circ} \mathrm{C}$ ) obtained with the thermal demagnetization of sIRM.

${ }^{\mathrm{b}} \mathrm{PO}$, porphyritic olivine cosmic spherule; S, stony cosmic spherule; V, glass cosmic spherule; BO, barred olivine cosmic spherule; G, G-type cosmic spherule; CC, cryptocrystalline cosmic spherule. 


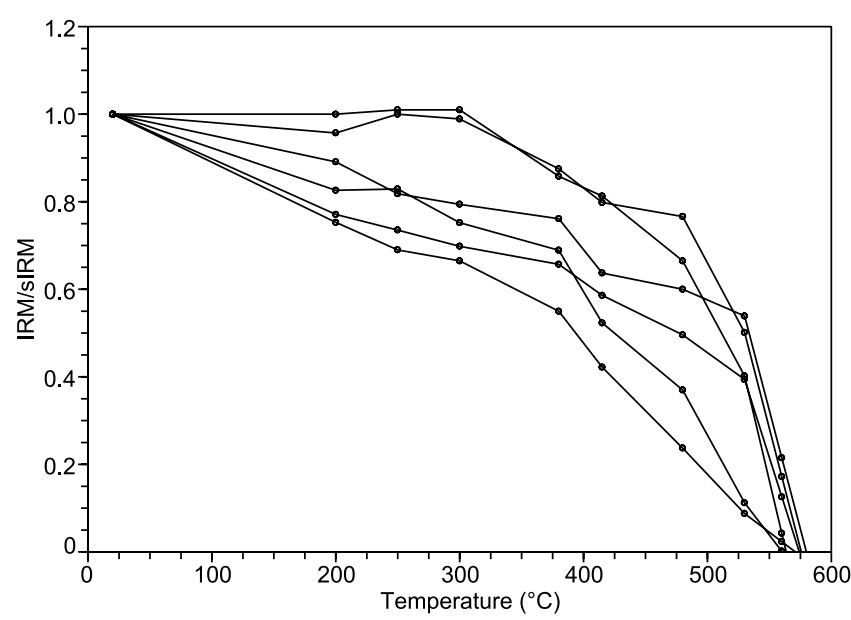

Figure 7. Stepwise thermal demagnetization of sIRM for selected cosmic spherules from Antarctica (Miller Butte sample).

of two populations of magnetite grains with different degrees of cation substitution within magnetite, the larger grains being more substituted. Within a single MM, magnetite grains could have different origins and grow in different redox and temperature conditions. Chemical analyses on individual magnetite grains would be necessary to confirm this hypothesis.

[22] Hysteresis loop measurements (Figure 8) give values for the coercive field $B_{c}$, saturation magnetization $M_{s}$, saturation remanent magnetization $M_{r s}$. A comparison between the value of $M_{r s}$ determined using the AGM and the sIRM measured with the $2 \mathrm{G}$ Enterprises DC Squid cryogenic magnetometer reveals that the AGM does not give reliable absolute values for $M_{r s}$ and $M_{s}$. Therefore, only their ratio is used in the following. The remanent coercive field $B_{c r}$ was determined by DC backfield demagnetization of the sIRM using the AGM. The Day plot [Day, 1977] (Figure 9) indicates that the magnetic inclusions in BO, PO and $\mathrm{CC}$ CSs have pseudosingle domain (PSD) to single domain (SD) grain sizes. SEM images and hysteresis measurements are in agreement, with smaller magnetite grains being single domain and larger grains having multidomain (MD) behavior. For each CS type, samples with smaller magnetite grains (Figure 2, samples $\mathrm{BOa}-\mathrm{BOb}$, $\mathrm{POa}-\mathrm{POb}$, and $\mathrm{CCa}-\mathrm{CCb}$ and Figure $8 \mathrm{~b}$ ) tend to have higher $M_{r s} / M_{s}$ ratios whereas samples with larger magnetite grains (Figure 2, samples $\mathrm{BOc}-\mathrm{BOe}, \mathrm{POc}-\mathrm{POe}$, and $\mathrm{CCc}$ and Figures $8 \mathrm{a}$ and $8 \mathrm{~d}$ ) have lower ratios. One glass $\mathrm{CS}$
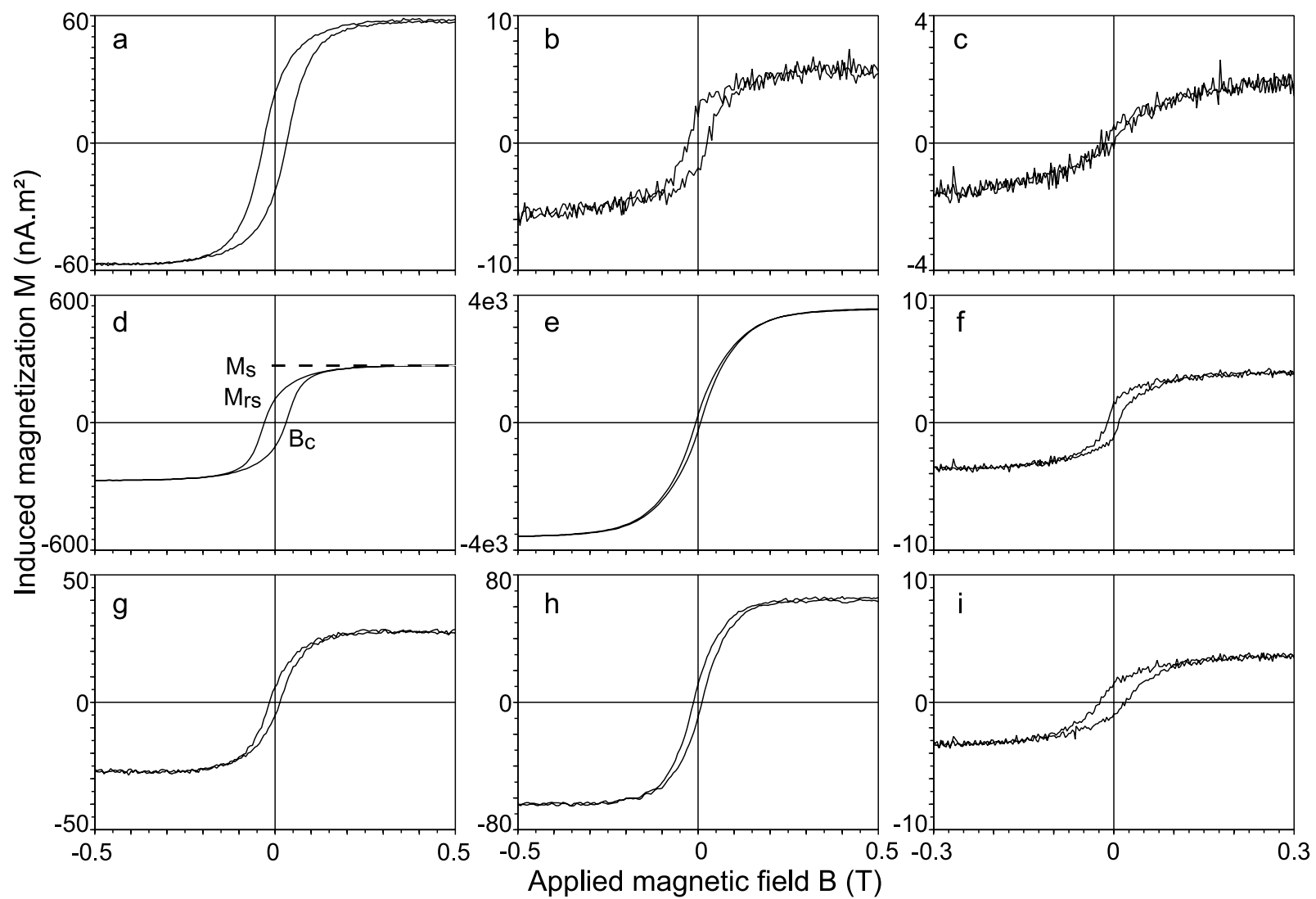

Figure 8. Hysteresis loops measured with a Princeton Measurements Corporation Alternating Field Magnetometer after correction of high-field slope (70\% interval). (a) Barred olivine cosmic spherule WAL-085 (m=24 $\mu \mathrm{g})$. (b) Porphyritic olivine cosmic spherule WAL-079 ( $\mathrm{m}=29 \mu \mathrm{g})$. (c) Glass cosmic spherule 03-40-06 (mean diameter $=102 \mu \mathrm{m}$ ). (d) Cryptocrystalline cosmic spherule FRO2-001 $(\mathrm{m}=53 \mu \mathrm{g})$. (e) I-type cosmic spherule FRO2-031 (m=73 $\mu \mathrm{g})$. (f) Fine-grained unmelted micrometeorite 05-37-23 (mean diameter $=204 \mu \mathrm{m})$. (g) Scoriaceous micrometeorite WAL-086 $(\mathrm{m}=24 \mu \mathrm{g})$. (h) G-type cosmic spherule WAL-096 (m $=24 \mu \mathrm{g})$. (i) Coarse-grained unmelted micrometeorite 05-37-22 (mean diameter $=230 \mu \mathrm{m})$. 


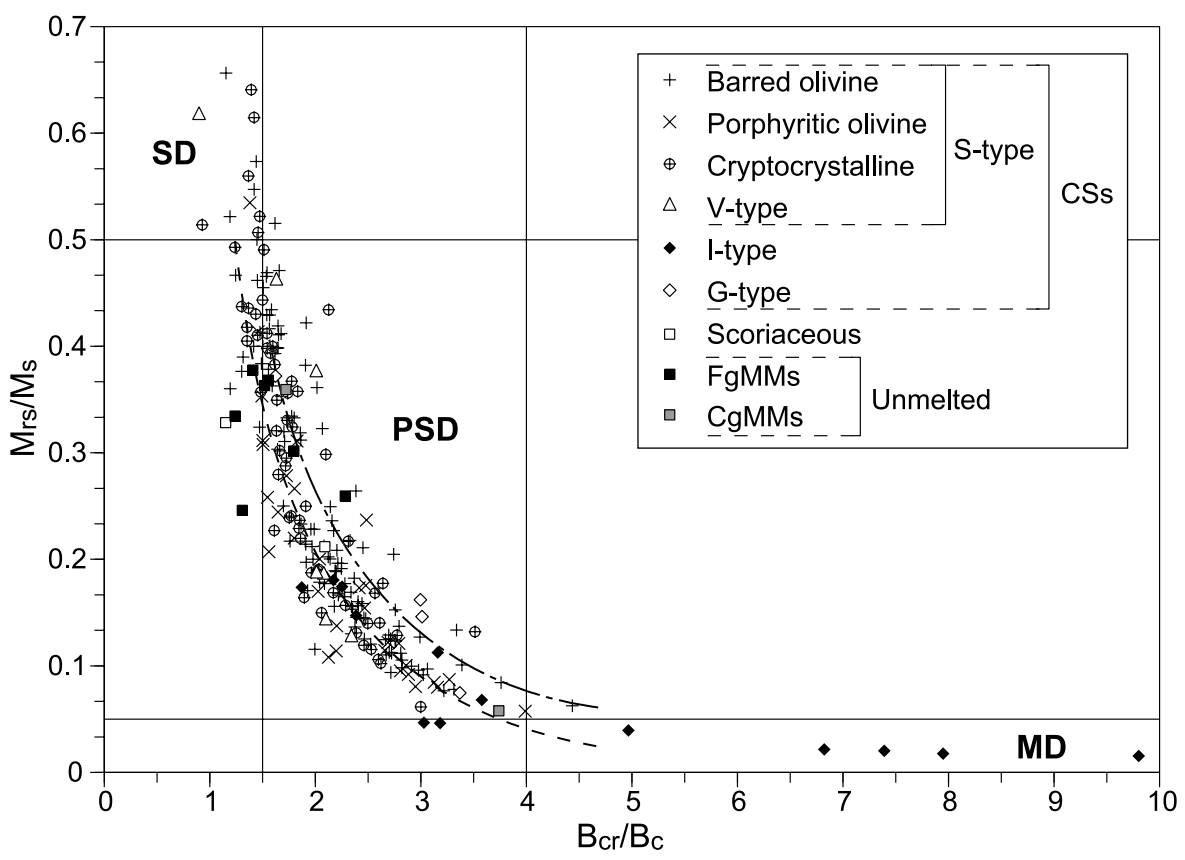

Figure 9. Day plot [Day, 1977] of the hysteresis parameters for different types of micrometeorites. The dashed and dashed-dotted curves are the mixing curves for a SD-MD mixture according to Day [1977] and Dunlop [2002], respectively.

sample (05-06-24) has SD magnetite inclusions, while other samples contain PSD magnetite (Figure 8c). Magnetite in I-type and G-type CSs has MD to PSD magnetic behavior. In I-type CSs with lower amounts of magnetite (Figure 1, Ia and Figure 8e) the magnetite is closer to a PSD domain state, whereas CSs with larger amounts of magnetite have higher $B_{c r} / B_{c}$ ratios (Figure 2, samples $\mathrm{Ib}-\mathrm{Ie}$ with increasing proportions of magnetite from $\mathrm{Ib}$ to $\mathrm{Ie}$ ). Among G-type CSs, samples with bigger magnetite dendrites (Figure 2, samples $\mathrm{Gd}-\mathrm{Ge}$ and Figure $8 \mathrm{~h}$ ) have lower $M_{r s} / M_{s}$ ratios (closer to MD magnetite values), whereas samples with finer magnetite dendrites (Figure 2, samples $\mathrm{Ga}-\mathrm{Gc}$ ) have hysteresis parameters that are closer to those expected for SD magnetite. The two measured ScMMs (FRO2-107 and WAL-086, Figure 8g) and FgMM 05-37-23 (Figure 8f) have PSD magnetite inclusions. Although metal and sulphides can be present as minor primary phases in FgMMs, their contribution to the magnetic properties is not evidenced by our hysteresis data. Of the two measured CgMMs, one (05-37-22) has PSD magnetite and the other (05-37-14, Figure 8i) has magnetic properties that are close to the border between PSD and MD magnetite. Xu et al. [1994] measured hysteresis properties of magnetite spherules extracted from limestone. Most spherules they measured show MD magnetic characteristics. According to our measurements, most magnetic spherules of extraterrestrial origin in sediments would show PSD grain size.

[23] Measured low-field total magnetic susceptibility values for $337 \mathrm{CSs}, 4 \mathrm{ScMMs}, 1 \mathrm{FgMM}$ and $1 \mathrm{CgMM}$ fall in the range of $4 \times 10^{-13}-1.1 \times 10^{-10} \mathrm{~m}^{3}$ (45 more MMs had susceptibilities below the noise level of the magnetic susceptibility meter used). The low-field volume magnetic susceptibility is represented as a function of particle diameter in Figure 10 for the Miller Butte, Frontier Mountain and Walcott Névé MMs. All of the data points above 1 SI are from I-type CSs. Owing to the sample bias caused by magnetic separation, these MMs are overrepresented in the Frontier Mountain sample. This bias and the fact that small diameter samples with low volume susceptibility are below the noise level of the magnetic susceptibility meter explain the apparent trend of increasing susceptibility with decreasing particle diameter. In order to scale the potential contribution of MMs to the susceptibility of sedimentary rocks in which they deposited, we calculated the limit above which the signal of a single MM exceeds that of a standard $8 \mathrm{~cm}^{3}$ sediment sample used in rock magnetic studies. Only few of the measured MMs have a susceptibility approaching that of a $10^{-5} \mathrm{SI}$ (low value for calcareous ooze or siliceous ooze) sediment sample (Figure 10). The probability for a sediment to have its magnetic susceptibility record biased by the presence of a MM is negligible for most sediments [Suavet et al., 2008].

[24] The volume susceptibility distributions for different types of MMs are shown in Figure 11. Owing to the uncertainty in the estimation of the volume of samples, the volume susceptibilities we give have a reliability of $\pm 10 \%$. Comparison with the value for pure magnetite $(\sim 3 \mathrm{SI}$ for a sphere) allows us to estimate the proportion of magnetite in the samples. As expected, there is a correlation between the volume susceptibility and the magnetite content observed on SEM images. Most $\mathrm{BO}$ and $\mathrm{CC}$ CSs have susceptibilities in the range of $0.03-0.8 \mathrm{SI}$. PO CSs have susceptibilities in the same range, but their peak is below 0.1 SI. Glass CSs have significantly lower volume susceptibilities, with the majority of samples in the range of $0.01-$ 0.1 SI. I-type CSs all have volume susceptibilities greater than $0.57 \mathrm{SI}$, and the peak of their distribution is in the range of 1-2.9 SI. G-type CSs can also have susceptibilities above $1 \mathrm{SI}$, but most samples are in the range of $0.1-0.3 \mathrm{SI}$. ScMMs have susceptibilities in the range of $0.07-0.12$ SI. 


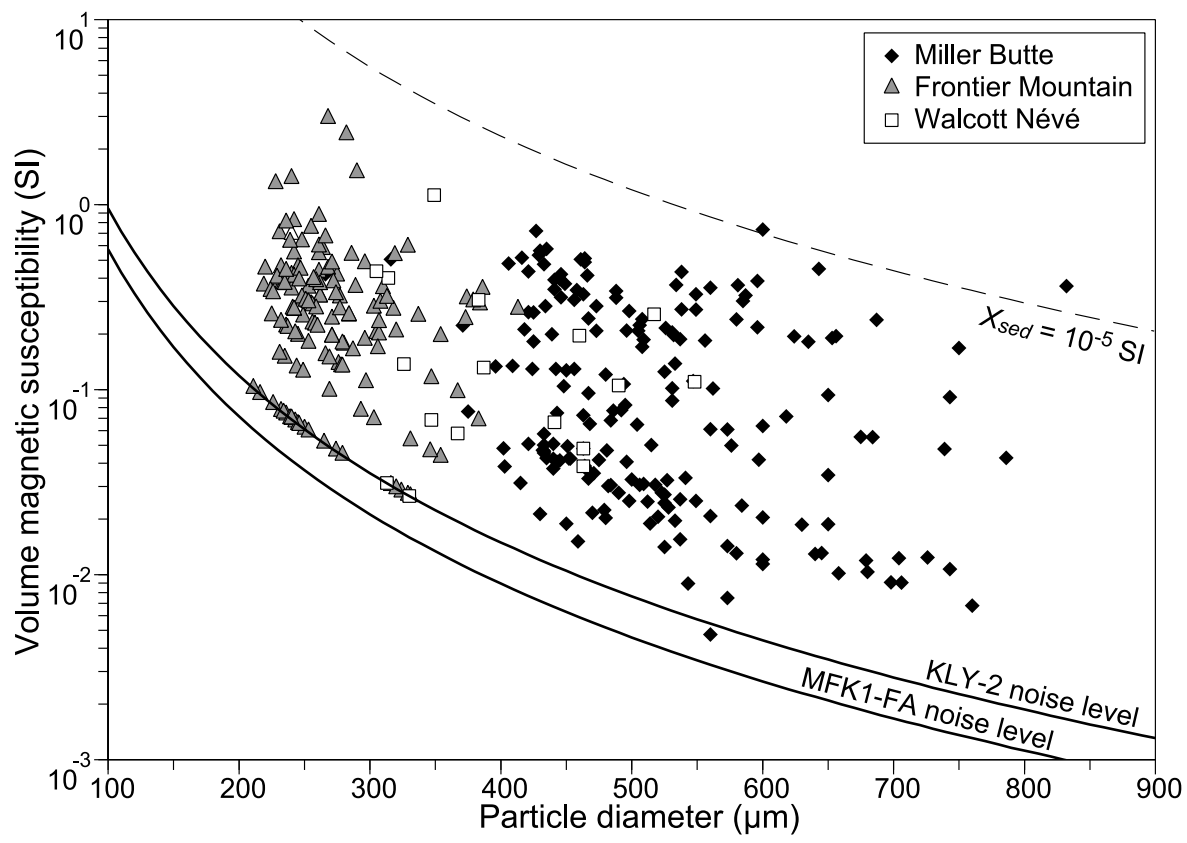

Figure 10. Volume magnetic susceptibility as a function of particle diameter for Miller Butte, Frontier Mountain, and Walcott Névé micrometeorites from Antarctica. The instrumental noise level is indicated with solid curves for the KLY 2 Kappabridge and MFK1-FA magnetic susceptibility meters, respectively. Samples that were below the noise level are represented on the noise level line. Dashed curves represent the limit above which the absolute susceptibility of a single micrometeorite exceeds that of an $8 \mathrm{~cm}^{3}$ sediment sample with a volume susceptibility $X_{\text {sed }}$ of $10^{-5} \mathrm{SI}$.

The 2 unmelted MMs measured, FgMM 05-37-23 and CgMM 05-37-14, have susceptibilities of 0.12 and $0.055 \mathrm{SI}$, respectively.

[25] The saturation magnetization $M_{S}$ (either directly measured with the VSM or calculated from the ratio $M_{r s} / M_{s}$ using the sIRM measured with the $2 \mathrm{G}$ Enterprises DC Squid cryogenic magnetometer) is plotted in Figure 12 as a function of the specific ferromagnetic susceptibility of MMs. The ferromagnetic susceptibility was obtained by subtracting the high-field susceptibility (the slope of the saturation moment in a hysteresis loop) from the total susceptibility (measured with KLY 2 or MFKA-FA magnetic susceptibility meters) [Rochette, 1987]. The data for most of the samples lie below the theoretically expected line for spheres of pure magnetite. This may be the consequence of two different effects: substitution in magnetite tends to reduce the value of $M_{s}$, and departure from sphericity increases the magnetic susceptibility, as shown with the theoretically expected line for elongated grains of pure magnetite [Rochette et al., 2003].

[26] The anisotropy of magnetic susceptibility was measured for 13 of the largest Miller Butte CSs (Table 2). They have an anisotropy degree (ratio of maximum to minimum susceptibility) in the range of $1.15-1.64$. The samples with the highest anisotropy degree (MIL-174 and MIL-022) are strongly anisometric samples (axial ratios of 1.79 and 1.35, respectively). The shape parameter $T$ [Jelinek, 1981] indicates oblate fabrics for most BO CSs. Sample MIL-104, with the highest positive value for $T$, has parallel olivine bars. BO CSs with lower positive values for $T$ either have less visible bars (MIL-020 and MIL-120) or more than one group of bars with different orientations (MIL-099). Sample
MIL-036 has visible olivine bars, yet its fabrics are only weakly oblate. Sample MIL-035 has a prolate fabric and its texture is intermediate between barred olivine and microcrystalline. Sample MIL-024 also has a prolate fabric, this sample has at least 5 populations of bars among which 3 intersect on an axis. The estimated shape anisotropy, the anisotropy of an object of the same shape with isotropic

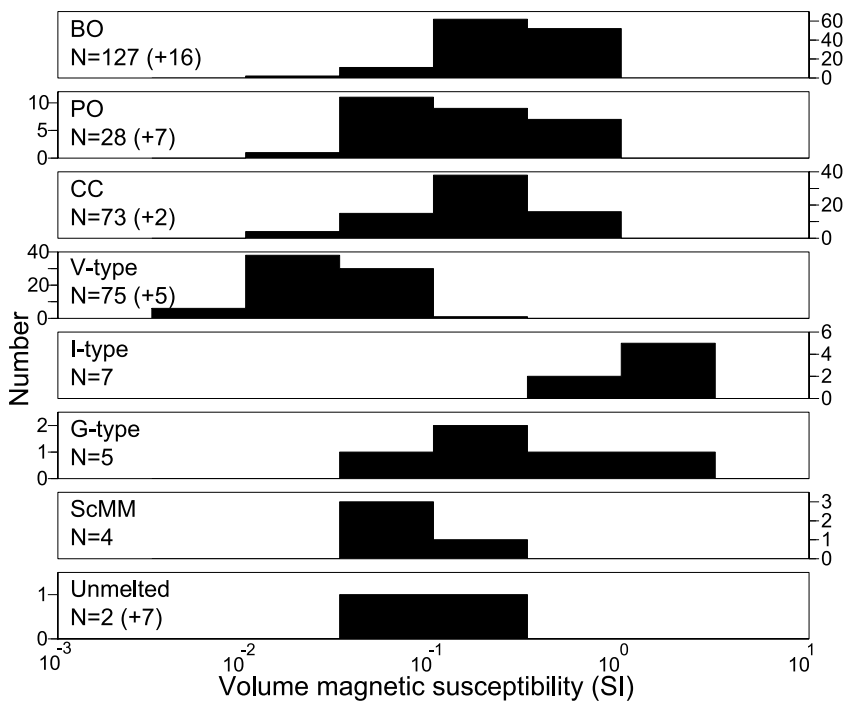

Figure 11. Volume magnetic susceptibility distributions for different types of micrometeorites. The bracketed numbers indicate how many samples were below the instrumental noise level. 


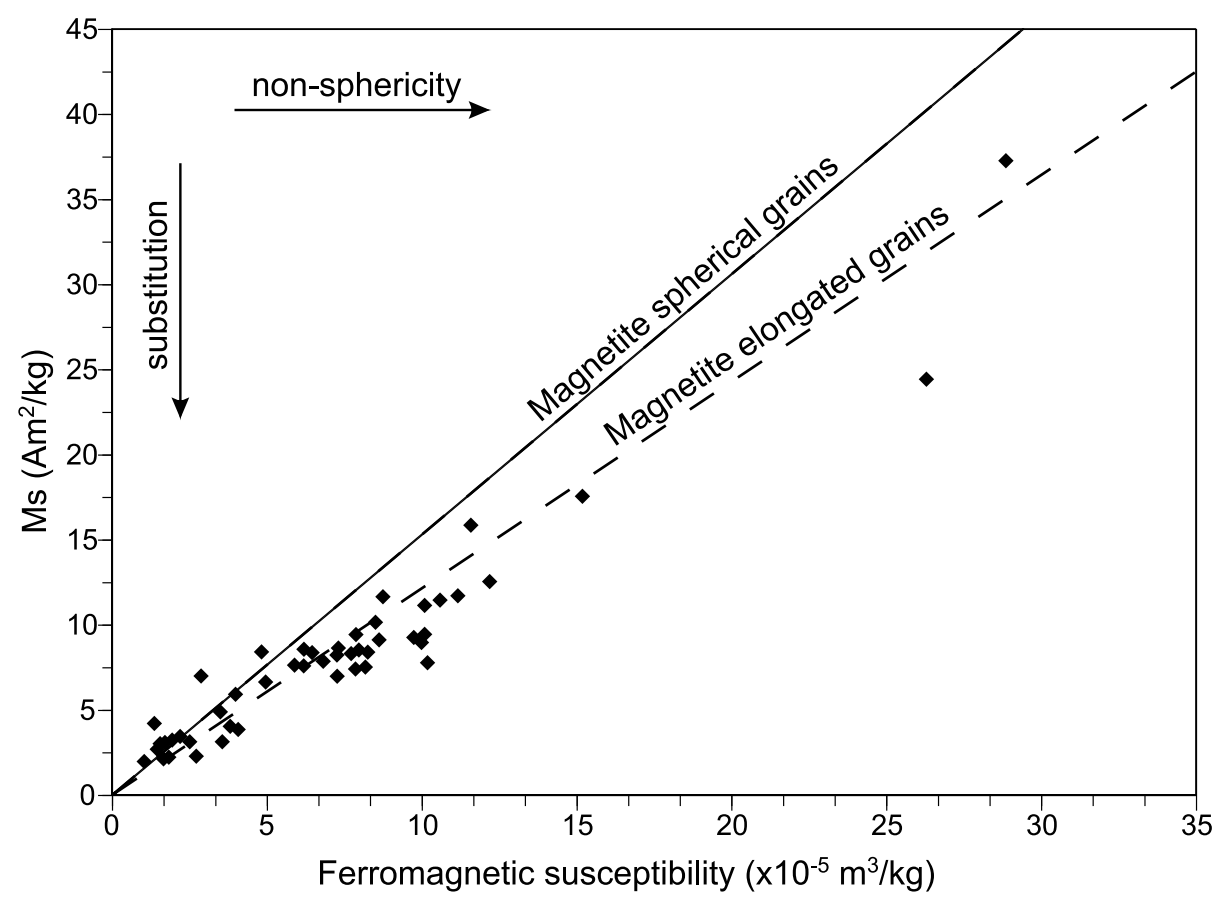

Figure 12. Saturation magnetization as a function of the mass ferromagnetic susceptibility. The theoretical curve for spheres of pure magnetite is given for comparison (slope $=1.53 \times 10^{5}$ ). The effects of substitution and departure from sphericity are shown with arrows. The dashed curve represents the theoretical slope for elongated grains of pure magnetite with an axial ratio of 2 [Rochette, 2003].

intrinsic susceptibility, is 1.07 for MIL-174, and 1.02 for MIL-022. This is much lower than their anisotropy degree $P$ (1.64 and 1.44, respectively). Therefore, the anisotropy of magnetic susceptibility of these samples is dominated by the orientation and distribution of magnetite grains within the silicate matrix. Of the three PO CSs measured, one has a slightly oblate fabric (MIL-023) and two have a prolate fabric (MIL-004 and MIL-006). The only measured G-type CS has a strongly oblate fabric.

\section{Natural Remanent Magnetization}

[27] The NRM of $230 \mathrm{CSs}, 4$ ScMMs and 4 unmelted MMs was measured (only samples that were not subjected to magnetic extraction were analyzed). The NRM was below the noise level of the magnetometer for $53 \mathrm{CSs}$ and for 1 ScMM. The sIRM was also measured for 76 of these CSs and for the 4 unmelted MMs. The NRM is in the range of $<10^{-10}-1.6 \times 10^{-7} \mathrm{Am}^{2}$. The volume magnetization is represented as a function of particle diameter in Figure 13 for the Miller Butte, Frontier Mountain, Walcott Névé and CONCORDIA collections. In order to scale the potential contribution of MMs to the NRM of sedimentary rocks in which they were deposited, we calculated the limit above which the NRM of a single MM exceeds that of a standard $8 \mathrm{~cm}^{3}$ sediment sample for different sediment magnetization values. All samples with NRM intensity above the noise level of the magnetometer have a stronger moment than a sediment sample with a $10^{-5} \mathrm{~A} / \mathrm{m}$ magnetization (lower range for siliceous/calcareous chalk or ooze), and some MMs have a moment exceeding that of a sediment sample with a $10^{-3} \mathrm{~A} / \mathrm{m}$ magnetization (deep sea clays for instance)

Table 2. Anisotropy of Magnetic Susceptibility ${ }^{\mathrm{a}}$

\begin{tabular}{|c|c|c|c|c|c|c|c|c|}
\hline Sample & Type & $\chi_{m}\left(\mathrm{~m}^{3}\right)$ & Standard Error $(\%)$ & $\chi_{n 1}$ & $\chi_{n 2}$ & $\chi_{n 3}$ & $P$ & $T$ \\
\hline MIL-004 & $\mathrm{PO}$ & $3.27 \times 10^{-11}$ & 6.36 & $1.15 \pm 0.05$ & $0.96 \pm 0.05$ & $0.89 \pm 0.05$ & 1.29 & -0.41 \\
\hline MIL-006 & $\mathrm{PO}$ & $3.40 \times 10^{-11}$ & 9.17 & $1.12 \pm 0.07$ & $0.99 \pm 0.07$ & $0.90 \pm 0.07$ & 1.25 & -0.10 \\
\hline MIL-020 & $\mathrm{BO}$ & $2.38 \times 10^{-11}$ & 1.31 & $1.06 \pm 0.01$ & $1.01 \pm 0.01$ & $0.93 \pm 0.01$ & 1.15 & 0.24 \\
\hline MIL-022 & $\mathrm{BO}$ & $2.38 \times 10^{-11}$ & 7.22 & $1.18 \pm 0.06$ & $0.99 \pm 0.06$ & $0.82 \pm 0.06$ & 1.44 & 0.05 \\
\hline MIL-023 & $\mathrm{PO}$ & $1.99 \times 10^{-11}$ & 4.18 & $1.07 \pm 0.03$ & $1.00 \pm 0.03$ & $0.93 \pm 0.03$ & 1.16 & 0.05 \\
\hline MIL-024 & $\mathrm{BO}$ & $2.95 \times 10^{-11}$ & 3.06 & $1.09 \pm 0.02$ & $0.96 \pm 0.02$ & $0.94 \pm 0.02$ & 1.16 & -0.68 \\
\hline MIL-035 & $\mathrm{BO}$ & $4.87 \times 10^{-11}$ & 3.74 & $1.07 \pm 0.03$ & $0.99 \pm 0.03$ & $0.93 \pm 0.03$ & 1.15 & -0.22 \\
\hline MIL-036 & $\mathrm{BO}$ & $2.58 \times 10^{-11}$ & 4.42 & $1.12 \pm 0.03$ & $1.00 \pm 0.03$ & $0.88 \pm 0.04$ & 1.27 & 0.08 \\
\hline MIL-073 & $\mathrm{G}$ & $2.82 \times 10^{-11}$ & 8.34 & $1.11 \pm 0.06$ & $1.03 \pm 0.06$ & $0.86 \pm 0.06$ & 1.29 & 0.38 \\
\hline MIL-099 & $\mathrm{BO}$ & $2.92 \times 10^{-11}$ & 10.30 & $1.10 \pm 0.08$ & $1.07 \pm 0.08$ & $0.90 \pm 0.08$ & 1.22 & 0.14 \\
\hline MIL-104 & $\mathrm{BO}$ & $2.33 \times 10^{-11}$ & 1.94 & $1.13 \pm 0.01$ & $1.05 \pm 0.02$ & $0.83 \pm 0.02$ & 1.36 & 0.52 \\
\hline MIL-120 & $\mathrm{BO}$ & $2.91 \times 10^{-11}$ & 2.12 & $1.08 \pm 0.02$ & $1.00 \pm 0.02$ & $0.92 \pm 0.01$ & 1.17 & 0.10 \\
\hline MIL-174 & $\mathrm{BO}$ & $8.42 \times 10^{-11}$ & 10.37 & $1.26 \pm 0.08$ & $0.97 \pm 0.08$ & $0.77 \pm 0.08$ & 1.64 & -0.04 \\
\hline
\end{tabular}

${ }^{\mathrm{a}} \chi_{m}$ is the mean susceptibility. $\chi_{n 1}, \chi_{n 2}$, and $\chi_{n 3}$ are the normed principal susceptibilities. $P$ is the anisotropy degree (ratio of maximum and minimum susceptibility). $T$ is the shape parameter $(T<0$ for prolate fabrics, $T>0$ for oblate fabrics [Jelinek, 1981]). 


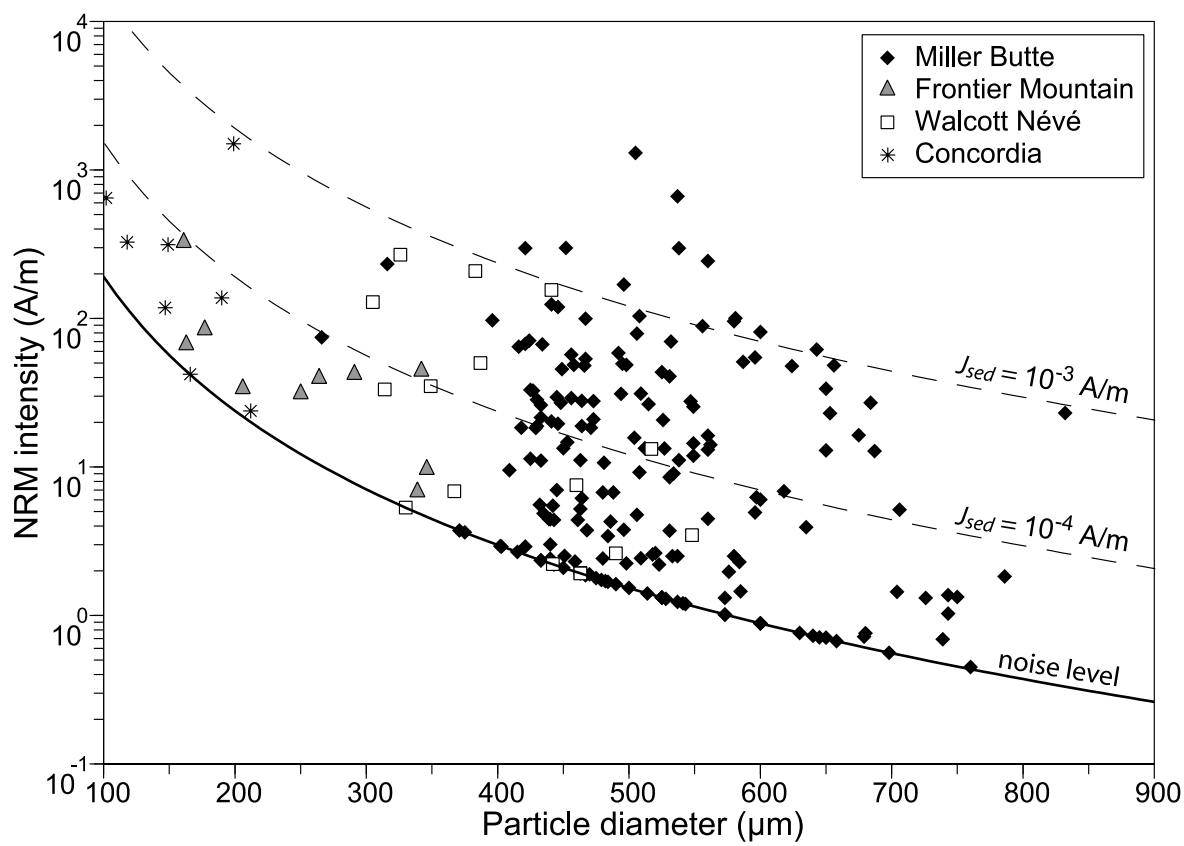

Figure 13. Natural remanent magnetization as a function of particle diameter for Miller Butte, Frontier Mountain, Walcott Névé, and CONCORDIA micrometeorites from Antarctica. The instrumental noise level is indicated with a solid curve. Samples that were below the noise level are represented on the noise level line. Dashed curves represent the limit above which the moment of a single micrometeorite exceeds that of an $8 \mathrm{~cm}^{3}$ sediment sample with a volume magnetization $J_{\text {sed }}$ of $10^{-4} \mathrm{~A} / \mathrm{m}$ or $10^{-3} \mathrm{~A} / \mathrm{m}$, respectively.

(Figure 13). According to Suavet et al. [2008], the probability for a sediment to have its magnetization direction biased of $>30^{\circ}$ is not negligible $(>1 \%)$ for sediments with magnetizations up to $5 \times 10^{-3} \mathrm{~A} / \mathrm{m}$ and sedimentation rates up to $10 \mathrm{~cm} / \mathrm{ka}$, and apparent reversals of polarity are possible (probability $>1 \%$ ) for sediments with low magnetizations $\left(<2 \times 10^{-4} \mathrm{~A} / \mathrm{m}\right)$ and low sedimentation rates $(<1 \mathrm{~cm} / \mathrm{ka})$. Although the Miller Butte and Frontier Mountain samples contain MMs with a terrestrial age of many tens of thousands of years, their magnetization range is not lower than that of 30-40 year old CONCORDIA MMs. The effect of terrestrial weathering on the magnetic properties of MMs therefore appears to be small. In particular, transformation of magnetite into maghemite does not seem to occur, as can be deduced from the reversible paths of temperature-dependent magnetic susceptibility analyses on Miller Butte samples (Figure 6).

[28] NRM intensity distributions for different types of CSs are shown in Figure 14. Owing to the uncertainty in the estimation of the volume of samples, the NRM intensities we give have a reliability of $\pm 10 \%$. BO and CC CSs have similar distributions, with a range of $\sim 1-300 \mathrm{~A} / \mathrm{m}$ and a peak at $10-100 \mathrm{~A} / \mathrm{m}$. PO CSs have lower NRM intensities on average, with a range of $1-55 \mathrm{~A} / \mathrm{m}$ and a peak below $10 \mathrm{~A} / \mathrm{m}$. Glass CSs have the lowest NRM intensities, most samples are in the range of $0.45-20 \mathrm{~A} / \mathrm{m}$. G-type CSs are in the range of $6.8-35 \mathrm{~A} / \mathrm{m}$. ScMMs have NRM intensities in the range of 3.7-16 A/m. The 3 FgMMs and CgMM 5-37-22 unmelted MMs have magnetization intensities among the highest values measured, with a range of $78-526 \mathrm{~A} / \mathrm{m}$. The NRM of the only analyzed I-type CS (16-160-1) is below the noise of the magnetometer because of its small volume.
[29] As CSs are quenched after melting during atmospheric entry, their NRM should be a thermal remanent magnetization (TRM) acquired in the Earth's magnetic field. Cap Prudhomme sample 05-13-01 and CONCORDIA sample 06-09-07 have NRM/sIRM [Fuller, 1974] ratios greater than 0.1 . Such a high ratio is unexpected for a

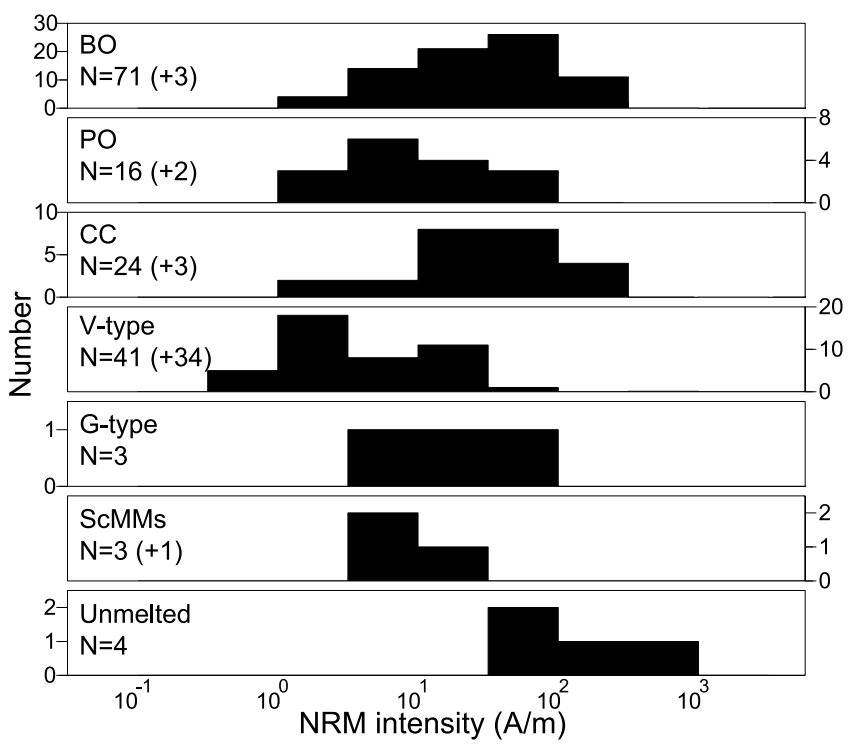

Figure 14. Natural remanent magnetization distributions for different types of micrometeorites. The numbers in parentheses indicate how many samples were below the instrumental noise level. 


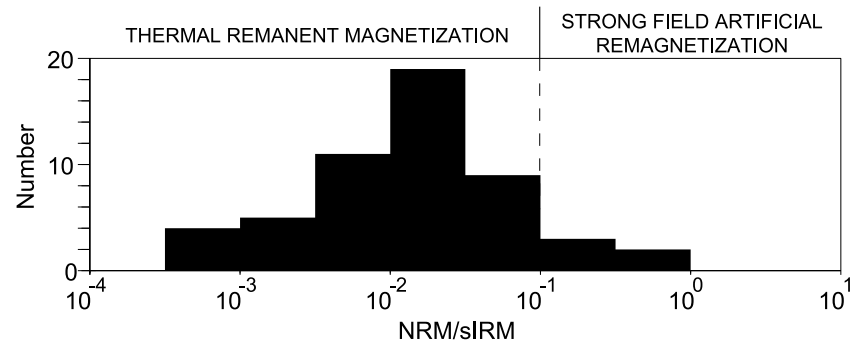

Figure 15. NRM/sIRM ratio distribution for all measured cosmic spherules. Ratios $<0.1$ are consistent with a thermal remanent magnetization acquired by quenching in the Earth's magnetic field during atmospheric entry. Ratios $>0.1$ may indicate that the samples have been remagnetized after entry by exposure to a strong $(>\mathrm{mT})$ magnetic field.
TRM. It might indicate that these samples have been artificially remagnetized after their entry through the Earth's atmosphere by exposure to a strong $(>\mathrm{mT})$ magnetic field. Figure 15 shows the distribution of NRM/sIRM ratios for all cosmic spherules we measured. All of the measured unmelted MMs from Cap Prudhomme collection also have $\mathrm{NRM} / \mathrm{sIRM}$ ratios greater than 0.1 . Remagnetization of these samples cannot be excluded, as they were collected many years ago without particular efforts to protect them from terrestrial and artificial magnetic fields, but most melted MMs from that collection have NRM/sIRM ratios below 0.1 (which indicates that they have not been artificially remagnetized). It is possible that the preatmospheric magnetization of unmelted MMs was not completely erased during atmospheric entry. Although temperature gradients are not supposed to develop in particles with diameter less than $\sim 600 \mu \mathrm{m}$ [Love and Brownlee, 1991], Flynn [2001] suggested that energy absorbing phases can allow temperature

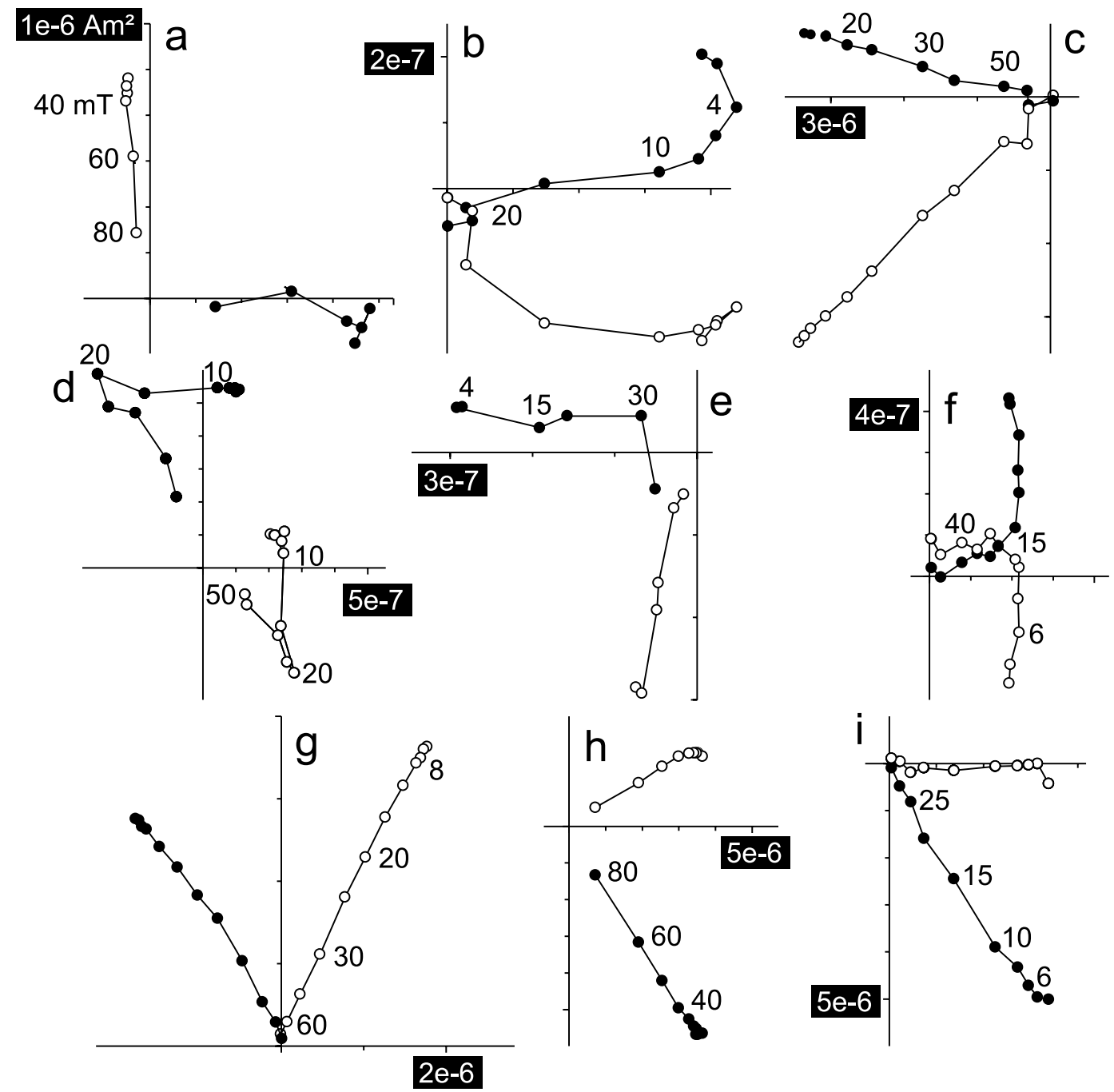

Figure 16. Orthogonal vector component plots of stepwise alternating field demagnetization data for the natural remanent magnetization of selected micrometeorites. (a) Glass cosmic spherule MIL-008. (b) Barred olivine cosmic spherule 06-09-33. (c) Cryptocrystalline cosmic spherule MIL-058. (d) Coarsegrained unmelted micrometeorite 05-37-22. (e) Fine-grained micrometeorite 05-37-19. (f) Barred olivine cosmic spherule FRO5-01. (g) Barred olivine cosmic spherule WAL-004. (h) Cryptocrystalline cosmic spherule WAL-011. (i) Porphyritic olivine cosmic spherule MIL-004. 
gradients to develop in smaller particles. He calculated that about $50 \%$ of the total mass (before entry and ablation) of particles in the $10-100 \mu \mathrm{g}$ mass range is not heated above $600^{\circ} \mathrm{C}$ during atmospheric entry. Conservation of the preatmospheric magnetization therefore seems to be possible in unmelted MMs. This magnetization could be carried by primary magnetite, as hysteresis data points toward magnetite as the main carrier of magnetization.

[30] Alternating field demagnetization of NRM and sIRM was carried out for 39 CSs and 4 unmelted MMs. Orthogonal vector component plots of demagnetization data for CSs often have a single magnetization component (Figures 16a and 16c and $16 \mathrm{~g}-16 \mathrm{i})$, but curved demagnetization trajectories are sometimes visible (Figures $16 \mathrm{~b}$ and 16f). This curvature might indicate that the MM was rotating during atmospheric entry while cooling in the Earth's field. In order to further investigate the nature of the magnetization, we used a different normalization technique, the normalization by isothermal remanent magnetization derivative vs. alternating field: $\mathrm{REM}^{\prime}=(\mathrm{dNRM} / \mathrm{dAF}) /(\mathrm{dIRM} / \mathrm{dAF})[$ Gattacceca and Rochette, 2004] are in the range of $10^{-3}-10^{-1}$, which is consistent with the magnetization being a TRM acquired in the Earth's field. Coarse-grained unmelted sample 05-37-22 (Figure 16d) has a two-component magnetization. As this sample has well-defined components different from the typical curvature observed in samples that have been remagnetized through contact with artificial magnets [Gattacceca and Rochette, 2004], it is unlikely that this sample was remagnetized after collection, unless one invokes two successive applications of magnets with decreasing strength. The two components have REM'>0.3, so the sample cannot have had a TRM acquired in the Earth's magnetic field during atmospheric entry. Finegrained unmelted sample 05-37-19 (Figure 16e) has a poorly determined single-component magnetization. The high coercivity components in samples with two-component magnetizations could represent preatmospheric magnetizations: the magnetization could be a remanent magnetization acquired in the early history of the protoplanetary disk in a strong field generated by the Sun ( $T$ Tauri phase) or by lightning discharging, or a TRM acquired on the asteroid parent body in a dynamo field, or a shock magnetization (see discussion in the work by, e.g., Gattacceca and Rochette [2004]).

\section{Conclusions}

[31] Magnetic measurements on melted cosmic spherules of different types allowed correlation of magnetic properties with the grain size of magnetite observed using electron microscopy. The volume magnetic susceptibility of cosmic spherules is in the range of $0.005-2.9$ SI. Anisotropy of magnetic susceptibility is in the range of $15-64 \%$, with most samples having oblate fabrics. The natural remanent magnetization of the cosmic spherules is a stable thermal remanent magnetization that was acquired during cooling in the Earth's magnetic field after melting in the atmosphere. The volume magnetization is in the range of $0.45-300 \mathrm{~A} / \mathrm{m}$. Curie temperatures deduced from susceptibility measurements at different temperatures are in the range of $485-$ $544^{\circ} \mathrm{C}$; maximum blocking temperatures determined from thermal demagnetization of micrometeorites have higher values in the range of $560-580^{\circ} \mathrm{C}$. The difference between these temperature estimations may be related to the presence of different populations of magnetite grains with different degrees of cation substitution.

[32] Measurements on scoriaceous micrometeorites, and on fine-grained and coarse-grained micrometeorites, gave susceptibilities in the range of $0.06-0.12$ SI. The magnetization of scoriaceous micrometeorites is in the range of $3.8-16 \mathrm{~A} / \mathrm{m}$. Unmelted micrometeorites have high magnetization intensities $(78-525 \mathrm{~A} / \mathrm{m})$ that could represent preatmospheric remanent magnetizations (acquired in a strong field in the early Solar System, in the dynamo field of the asteroid parent body, or by shock magnetization), or remagnetizations that occurred after atmospheric entry of the samples.

[33] Micrometeorites are tiny objects, but their high magnetite content gives them higher magnetic susceptibility and magnetization than most terrestrial rocks. Therefore, a single micrometeorite deposited in a sediment may induce a significant bias in the magnetic properties of the sedimentary rock at the scale of samples used for paleomagnetic studies [Suavet et al., 2008].

[34] Acknowledgments. We would like to thank S. Gilder, A. Roberts, J. Gee, S. Brachfeld, and T. von Dobeneck for their comments on this work and C. Engrand for providing micrometeorites from the CONCORDIA, Cap Prudhomme, and Greenland collections. This work was supported by the French Agence Nationale de la Recherche (project ANR-05-JCJC-0133).

\section{References}

Basile, I., J. R. Petit, S. Touron, F. E. Grousset, and N. Barkor (2001), Volcanic layers in Antarctic (Vostok) ice cores: Source identification and atmospheric implications, J. Geophys. Res., 106, 31,915-31,931.

Curzio, P., L. Folco, M. A. Laurenzi, M. Mellini, and A. Zeoli (2008), A tephra chronostratigraphic framework for the Frontier Mountain blue-ice field (northern Victoria Land, Antartctica), Quat. Sci. Rev., 27, 602-620.

Day, R. (1977), Hysteresis properties of titanomagnetites: Grain-size and compositional dependance, Phys. Earth Planet. Inter., 13, 260-267.

Dunlop, D. (2002), Theory and application of the Day plot $\left(M_{r s} / M_{s}\right.$ versus $\left.H_{c r} / H_{c}\right)$ : 1. Theoretical curves and tests using titanomagnetite data, J. Geophys. Res., 107(B3), 2056, doi:10.1029/2001JB000486.

Dunlop, D. J., and Ö. Özdemir (2001), Rock Magnetism: Fundamentals and Frontiers, Cambridge Stud. Magn., vol. 3, 596 pp., Cambridge Univ. Press, Cambridge, U. K.

Duprat, J., C. Engrand, M. Maurette, G. Kurat, M. Gounelle, and C. Hammer (2007), Micrometeorites from central Antarctic snow: The CONCORDIA collection, Adv. Space Res., 392, 605-611, doi:10.1016/j.asr.2006.05.029.

Flynn, G. J. (2001), Atmospheric entry heating of interplanetary dust, in Accretion of Extraterrestrial Matter Throughout Earth's History, edited by B. Peucker-Ehrenbrink and B. Schmitz, pp. 107-127, Kluwer Acad., New York.

Folco, L., P. Rochette, N. Perchiazzi, M. D’Orazio, M. A. Laurenzi, and M. Tiepolo (2008), Microtektites from Victoria Land Transantarctic Mountains, Geology, 36, 291-294, doi:10.1130/G24528A.1.

Fuller, M. (1974), Lunar magnetism, Rev. Geophys., 12, 23-70.

Gattacceca, J., and P. Rochette (2004), Toward a robust normalized magnetic paleointensity method applied to meteorites, Earth Planet. Sci. Lett., 227, 377-393, doi:10.1016/j.eps1.2004.09.013.

Genge, M. J., C. Engrand, M. Gounelle, and S. Taylor (2008), The classification of micrometeorites, Meteorit. Planet. Sci., 43, 497-515.

Grommé, C. S., T. L. Wright, and D. L. Peck (1969), Magnetic properties and oxidation of iron-titanium oxide minerals in Alae and Makaopuhi lava lakes, Hawaii, J. Geophys. Res., 74, 5277-5294.

Hammersley, A. P. (1997), FIT2D: An introduction and overview, ESRF Internal Rep. ESRF97HA02T, Eur. Synchrotron Radiat. Facil., Grenoble, France.

Harvey, R. P., and M. Maurette (1991), The origin and significance of cosmic dust from the Walcott Névé, Antarctica, Proc. Lunar Planet. Sci. Conf., 21, 569-578.

Jelinek, V. (1981), Characterization of the magnetic fabric of rocks, Tectonophysics, 79, 63-67. 
LeMasurier, W. E., and J. W. Thomson (1990), Volcanoes of the Antarctic Plate and Southern Oceans, Antarct. Res. Ser., vol. 48, 487 pp., AGU, Washington, D.C.

Love, S. G., and D. E. Brownlee (1991), Heating and thermal transformation of micrometeoroids entering the Earth's atmosphere, Icarus, 89, 26-43.

Love, S. G., and D. E. Brownlee (1993), A direct measurement of the terrestrial mass accretion rate of cosmic dust, Science, 262, 550-553.

Marfaing, J., P. Rochette, J. Pellerey, P. Chaurand, C. Suavet, and L. Folco (2008), Study of a set of micrometeorites from Antarctica using magnetic and ESR methods coupled with micro-XRF, J. Magn. Magn. Mater., 320, 1687-1695, doi:10.1016/j.jmmm.2008.01.037.

Maurette, M., C. Hammer, D. E. Brownlee, N. Reeh, and H. H. Thomsen (1986), Placers of cosmic dust in the blue lakes of Greenland, Science, 233, 869-872.

Maurette, M., C. Olinger, M. Christophe Michel-Levy, G. Kurat, M. Pourchet, F. Brandstätter, and M. Bourot-Denise (1991), A collection of diverse micrometeorites recovered from 100 tonnes of Antarctic blue ice, Nature, 351, 44-46.

McManus, D. A., et al. (1970), Site 38, Initial Rep. Deep Sea Drill. Proj., 5, 255-296.

Petrovský, E., and A. Kapièka (2006), On determination of the Curie point from thermomagnetic curves, J. Geophys. Res., 111, B12S27, doi:10.1029/2006JB004507.

Robin, E., P. Bonth, L. Froget, C. Jhanno, and R. Rocchia (1992), Formation of spinels in cosmic objects during atmospheric entry: A clue to the CretaceousTertiary boundary event, Earth Planet. Sci. Lett., 108, 181-190.

Rochette, P. (1987), Magnetic susceptibility of the rock matrix related to magnetic fabric studies, J. Struct. Geol., 9, 1015-1020.

Rochette, P., L. Sagnotti, G. Consolmagno, M. Denise, L. Folco, J. Gattacceca, M. Osete, and L. Pesonen (2003), Magnetic classification of stony meteorites: 1. Ordinary chondrites, Meteorit. Planet. Sci., 38, 251-268.

Rochette, P., et al. (2008a), Magnetic classification of stony meteorites: 2. Non-ordinary chondrites, Meteorit. Planet. Sci., 43, 959-980.

Rochette, P., L. Folco, C. Suavet, M. van Ginneken, J. Gattacceca, N. Perchiazzi, R. Braucher, and R. P. Harvey (2008b), Micrometeorites from the Transantarctic Mountains, Proc. Natl. Acad. Sci. U. S. A., 105, 18,206-18,211, doi:10.1073/pnas.0806049105.
Suavet, C., P. Rochette, J. Gattacceca, and L. Folco (2008), Micrometeorites: A possible bias on the sedimentary magnetic record, Geochem. Geophys. Geosyst., 9, Q11002, doi:10.1029/2008GC002160.

Taylor, S., and J. H. Lever (2001), Seeking unbiased collections of modern and ancient micrometeorites, in Accretion of Extraterrestrial Matter Throughout Earth's History, edited by B. Peucker-Ehrenbrink and B. Schmitz, pp. 205-219, Kluwer Acad., New York.

Taylor, S., J. H. Lever, and R. P. Harvey (1998), Accretion rate of cosmic spherules measured at the South Pole, Nature, 392, 899-903.

Taylor, S., J. H. Lever, and R. P. Harvey (2000), Numbers, types and composition of an unbiased collection of cosmic spherules, Meteorit. Planet. Sci., 35, 651-666.

Toppani, A., and G. Libourel (2003), Factors controlling compositions of cosmic spinels: Application to atmospheric entry conditions of meteoritic materials, Geochim. Cosmochim. Acta, 67, 4621-4638.

Toppani, A., G. Libourel, C. Engrand, and M. Maurette (2001), Experimental simulation of atmospheric entry of micrometeorites, Meteorit. Planet. Sci., 36, 1377-1396.

van Andel, T. H., et al. (1973), Site 160, Initial Rep. Deep Sea Drill. Proj., $16,265-299$

Xu, W., R. van der Voo, and D. R. Peacor (1994), Are magnetite spherules capable of carrying stable magnetizations?, Geophys. Res. Lett., 21, 517520 .

J. Duprat, CSNSM, Batiment 104, F-91406 Orsay, France.

L. Folco, Museo Nazionale dell'Antartide, Universit di Siena, Via Laterina 8, I-53100 Siena, Italy.

J. Gattacceca, P. Rochette, and C. Suavet, CEREGE, Aix-Marseille Université, CNRS, Europôle Médipteraléen de l'Arbois, BP 80, F-13545 Aix-en-Provence, CEDEX 04, France. (suavet@cerege.fr)

R. P. Harvey, Department of Geological Sciences, Case Western Reserve University, Cleveland, $\mathrm{OH} 44106$, USA.

N. Perchiazzi, Dipartimento di Scienze della Terra, Università di Pisa, Via S. Maria 53, I-56126 Pisa, Italy. 